\title{
Investment Hangover and the Great Recession
}

\section{Citation}

Rognlie, Matthew, Andrei Shleifer, and Alp Simsek. 2014. Investment Hangover and the Great Recession. Working paper, Harvard University.

\section{Published Version}

http://scholar.harvard.edu/shleifer/node/203866

\section{Permanent link}

http://nrs.harvard.edu/urn-3:HUL.InstRepos:17491855

\section{Terms of Use}

This article was downloaded from Harvard University's DASH repository, and is made available under the terms and conditions applicable to Open Access Policy Articles, as set forth at http:// nrs.harvard.edu/urn-3:HUL.InstRepos:dash.current.terms-of-use\#OAP

\section{Share Your Story}

The Harvard community has made this article openly available.

Please share how this access benefits you. Submit a story.

\section{Accessibility}




\title{
Investment Hangover and the Great Recession*
}

\author{
Matthew Rognlie $\quad$ Andrei Shleifer ${ }^{\ddagger} \quad$ Alp Simsek ${ }^{\S}$ \\ July 2015
}

\begin{abstract}
We present a model of investment hangover motivated by the Great Recession. Overbuilding of residential capital requires a reallocation of productive resources to nonresidential sectors, which is facilitated by a reduction in the real interest rate. If the interest rate is constrained, the economy features a recession with limited reallocation and low output. Nonresidential investment initially declines due to low demand, but later booms due to low interest rates. The boom induces an asymmetric recovery in which the overbuilt sector is left behind. Welfare can be improved by ex-post policies that slow down disinvestment, and ex-ante policies that restrict investment.
\end{abstract}

JEL Classification: E32, E22, E4

Keywords: The Great Recession, housing, overbuilding, reallocation, liquidity trap, zero lower bound, investment, capital, accelerator, aggregate demand externality.

*We thank Jennifer La'o, John Leahy, Guido Lorenzoni, Monika Piazzesi, Giacomo Ponzetto, John Shea, Nancy Stokey, Michael Woodford, and Kamil Yilmaz for helpful comments. We also thank the seminar participants at the BIS, Columbia University, Cornell University, Georgetown University, the Institute for International Economic Studies, London Business School, MIT, Northwestern University, Norwegian Business School, Princeton University, the Sveriges Riksbank, Stanford University, the University of Chicago; and the conference participants at the Bank of Portugal Conference on Monetary Economics, the CSEF-CIM-UCL Conference, Koc Winter Workshop, the SED Annual Meeting, and the NBER Summer Institute for their comments.

†MIT, mrognlie@mit.edu

${ }^{\ddagger}$ Harvard University and NBER, shleifer@fas.harvard.edu

§MIT and NBER, asimsek@mit.edu 


\section{Introduction}

Since 2008, the US economy has been going through the worst macroeconomic slump since the Great Depression. Real GDP per capita declined from more than $\$ 49,000$ in 2007 (in 2009 dollars) to less than $\$ 47,000$ in 2009, and surpassed its pre-recession level only in 2013. The civilian employment ratio, which stood at about $63 \%$ in January 2008, fell below $59 \%$ by the end of 2009 , and remained below $59.5 \%$ in June 2015.

Recent macroeconomic research emphasizes the boom bust cycle in house pricesand its effects on financial institutions, firms, and households - as the main culprit for these developments. The collapse of home prices arguably affected the economy through at least two principal channels. First, financial institutions that suffered losses related to the housing market cut back their lending to firms and households (Brunnermeier (2009), Gertler and Kiyotaki (2010)). Second, homeowners that had borrowed against rising collateral values during the boom phase faced tighter borrowing constraints and had to reduce their outstanding leverage (Guerrieri and Lorenzoni (2011), Eggertsson and Krugman (2012), Mian and Sufi (2014)). Both channels reduced aggregate demand, plunging the economy into a Keynesian recession. The recession was exacerbated by the zero lower bound on the nominal interest rate, also known as the liquidity trap, which restricted the ability of monetary policy to counter these demand shocks (Hall (2011), Christiano, Eichenbaum, Trabandt (2014)).

A growing body of empirical evidence shows that these views are at least partially correct: the financial and the household crises both appear to have played a part in the Great Recession 11 But these views also face a challenge in explaining the nature of the recovery after the Great Recession. The recovery has been quite asymmetric across components of aggregate private spending. As the right panel of Figure 1 illustrates, nonresidential investment - measured as a fraction of output - almost reached its pre-recession level by 2015, while residential investment remained depressed. One explanation for this pattern is that households are unable to buy homes due to ongoing deleveraging. But the right panel of Figure 1 casts doubt on this explanation: sales of durables not directly related to housing such as cars - which should also be affected by household deleveraging - rebounded strongly in recent years while sales of new homes have lagged behind. Another potential explanation is that the US

\footnotetext{
${ }^{1}$ Several recent papers, such as Campello, Graham, and Harvey (2010) and Chodorow-Reich (2014), provide some evidence that financial crisis affected firms' investment before 2010. Mian, Rao, Sufi (2013) and Mian and Sufi (2014, 2015) provide evidence that household deleveraging reduced household consumption and employment between 2007 and 2009.
} 


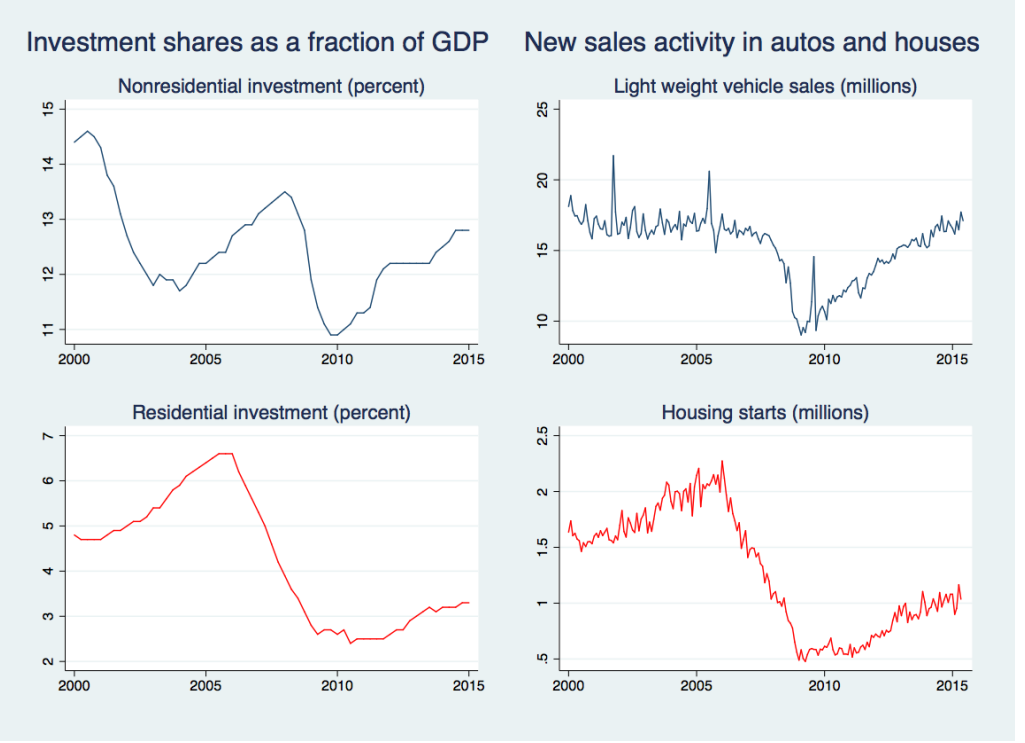

Figure 1: The left panels plot the two components of investment in the US as a share of GDP. The right panels plot new sales of autos and light trucks (top) and housing starts (bottom). Source: St. Louis Fed.

residential investment generally lags behind in recoveries. This explanation is also incorrect: Leamer (2007) analyzes the post-war recessions in the US and shows that residential investment typically recovers before nonresidential investment and other consumer durables.

In this paper, we supplement the two accounts of the Great Recession with a third channel, which we refer to as the investment hangover, which could help to explain the asymmetric recovery. Our key observation is that there was also an investment boom in the housing market, in addition to the price boom. Overbuilding during the boom years created excess supply of housing capital by 2007, especially of owner occupied housing. The top panel of Figure2 2 illustrates that, between 1996 and 2005, the share of US households living in their own homes rose from about $65 \%$ to about $69 \%$. The homeownership rate fell back below $65 \%$ in 2014, suggesting that owner occupied housing capital might have been in excess for many years after 2005.

How does the economy decumulate the excess stock of housing capital? We address this question by using a stylized macroeconomic model. Our model's first prediction is that the excess housing capital lowers residential investment. This is because housing capital is highly durable, and thus, an excess of initial stock substitutes for new investment. The bottom panel of Figure 2 provides evidence consistent with this prediction. The sales of newly constructed homes, which have historically changed 


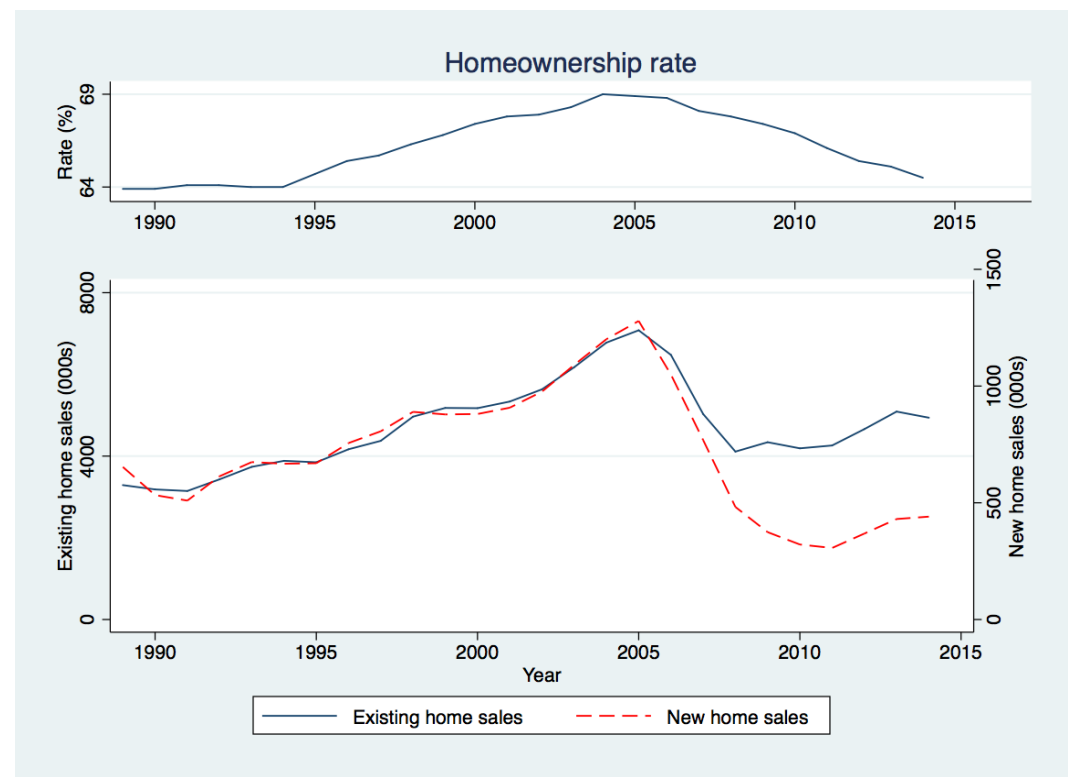

Figure 2: The top panel plots the homeownership rate in the US (source: US Bureau of the Census). The bottom panel plots the total sales of existing and new homes (source: National Association of Realtors).

in proportion to the sales of existing homes, fell disproportionately starting around 2005.

Our argument so far is similar to the Austrian theory of the business cycle, in which recessions are times at which the economy liquidates the excess capital built during boom years (Hayek (1931)). The Hayekian view, however, faces a challenge in explaining how low investment in the liquidating sector reduces aggregate output and employment. As noted by Krugman (1998), the economy has a natural adjustment mechanism that facilitates the reallocation of labor (and other productive resources) from the liquidating sector to other sectors. As economic activity in the liquidating sector declines, the interest rate falls and stimulates spending in other sectors, which keeps employment from falling. This reallocation process can be associated with some increase in frictional unemployment. But it is unclear in the Austrian theory how employment can fall in both the liquidating and the nonliquidating sectors, which seems to be the case for major recessions such as the Great Recession. To fit that evidence, an additional - Keynesian - aggregate demand mechanism is needed.

Accordingly, we depart from the Hayekian view by emphasizing that, during the Great Recession, the aggregate reallocation mechanism was undermined by the zero lower bound constraint on monetary policy. If the initial overbuilding is sufficiently 
large, then the interest rate hits a lower bound and the economy enters a liquidity trap. As this happens, low investment in the residential sector cannot be countered by the expansion of other sectors. Instead, low investment reduces aggregate demand and output, contributing to the Keynesian slump.

Our model also reveals that the slowdown in the liquidating sector can naturally spill over to other sectors. The Keynesian slump reduces the return to nonresidential capital, such as equipment and machines, in view of the low demand. This can generate an initial reduction in nonresidential investment, despite the low interest rate and the low cost of capital. As the economy liquidates the excess residential capital, nonresidential investment gradually recovers in anticipation of a recovery in output. From the lens of our model, then, the recession can be roughly divided into two phases. In the first phase, both types of investment decline, generating a severe and widespread slump. In the second phase, nonresidential investment rises, generating a partial recovery, but residential investment remains low. The residential sector is left behind in the recovery, as in Figure 1 .

We finally investigate the implications of our analysis for policies directed towards controlling investment. A naive intuition would suggest that the planner should not interfere with residential disinvestment, since the problems originate in this sector. We find that this intuition is incorrect: if the recession is sufficiently severe, then the planner optimally stimulates residential investment and slows down the decumulation. This result is driven by two observations. First, the planner recognizes that raising investment in a liquidity trap stimulates aggregate demand and employment. In view of these aggregate demand externalities, the planner perceives a lower cost of building compared to the private sector. The lower cost, by itself, is not sufficient reason for intervention - the planner also considers the benefits. The second observation is that the return from residential investment is not too low, even when housing is overbuilt and generates low flow utility in the short run, because housing capital is very durable. Stimulating residential investment is beneficial because it helps to economize on future residential investment.

We also find that, before the economy enters the overhang episode, the planner optimally restricts investment - including nonresidential investment. Intuitively, the planner reduces the accumulation of capital in earlier periods, so as to stimulate investment and aggregate demand during the liquidity trap. Moreover, the intervention is more desirable for more durable types of capital, because durability is the link by which past investment affects future economic activity. Taken together, our welfare analysis supports policies that intertemporally substitute investment towards periods 
that feature deficient demand, especially for long-lived capital such as housing or structures.

The rest of the paper is organized as follows. The next subsection discusses the related literature. Section 2 describes the basic environment, defines the equilibrium, and establishes the properties of equilibrium that facilitate subsequent analysis. The remaining sections characterize the dynamic equilibrium starting with excess residential capital. Section 3 presents our main result that excessive overbuilding induces a recession, and establishes conditions under which this outcome is more likely. Section 4 investigates the nonresidential investment response, and discusses the relationship of our model with the acceleration principle of investment. Section 5 analyzes the policy implications of our analysis and Section 6 concludes.

\subsection{Related literature}

Our paper makes contributions to several strands of the literature. First, we identify the ex-ante overbuilding of housing as an important source of deficient aggregate demand during the Great Recession. A large literature emphasizes other types of demand shocks such as those driven by financial frictions or household deleveraging.2 Other papers emphasize long-run factors that might have lowered demand more persistently (Summers (2013), Eggertsson and Mehrotra (2014), Caballero and Farhi (2014)). Our paper complements this literature and provides an explanation for why residential investment has lagged behind in the recovery.

Another strand of the literature investigates the role of housing during the Great Recession, but often focusing on channels other than overbuilding. Many papers, e.g., Iacoviello and Pavan (2013), emphasize the collateral channel by which housing might have tightened household borrowing constraints. Kaplan and Violante (2015) emphasize that the high-returns associated with (illiquid) housing wealth might have increased the number of constrained households in equilibrium. ${ }^{3}$ Boldrin et al. (2013) also emphasize overbuilding, but they do not analyze the resulting deficient demand problem. Instead, they focus on the supply-side input-output linkages by which the

\footnotetext{
${ }^{2}$ In addition to the papers mentioned earlier, see also Gertler and Karadi (2011), Midrigan and Philippon (2011), Jermann and Quadrini (2012), He and Krishnamurthy (2014) for quantitative dynamic macroeconomic models that emphasize either banks', firms', or households' financial frictions during the Great Recession.

${ }^{3}$ There is also a large literature that develops quantitative business cycle models with housing, but without focusing on the Great Recession or overbuilding, e.g., Greenwood and Hercowitz (1991), Gervais (2002), Iacoviello (2005), Campbell and Hercowitz (2005), Davis and Heathcote (2005), Fisher (2007), Piazzesi, Schneider, and Tuzel (2007), Kiyotaki, Michaelides, and Nikolov (2011).
} 
slowdown in construction spills over to other sectors.

Second, and more broadly, we illustrate how having too much of a durable good can trigger a recession. As DeLong (1990) discusses, Hayekian (or liquidationist) views along these lines were quite popular before and during the Great Depression, but were relegated to the sidelines with the Keynesian revolution in macroeconomics. Our paper illustrates how Hayekian and Keynesian mechanisms can come together to generate a recession. The Hayekian mechanism finds another modern formulation in the recent literature on news-driven business cycles. A strand of this literature argues that positive news about future productivity can generate investment booms, occasionally followed by liquidations if the news is not realized (see Beaudry and Portier (2013) for a review). This literature typically generates business cycles from supply side considerations (see, for instance, Beaudry and Portier (2004), Jaimovich and Rebelo (2009)), whereas we emphasize a demand side channel.

In recent and complementary work, Beaudry, Galizia, Portier (BGP, 2014) also investigate whether overbuilding can induce a recession driven by deficient demand. In BGP, aggregate demand affects employment due to a matching friction in the labor market, whereas we obtain demand effects through nominal rigidities. In addition, BGP show how overbuilding increases the (uninsurable) unemployment risk, which exacerbates the recession due to households' precautionary savings motive. We describe how overbuilding exacerbates the recession due to the endogenous nonresidential investment response $4^{4}$

Third, our analysis illustrates how a constrained monetary policy, e.g., due to the liquidity trap, restricts the efficient reallocation of resources between sectors. A large macroeconomics literature investigates the role of reallocation shocks relative to aggregate activity shocks in generating unemployment (see, for instance, Lilien (1982), Abraham and Katz (1986), Blanchard and Diamond (1989), Davis and Haltiwanger (1990)). Our paper shows that the constrained monetary policy blurs the line be-

\footnotetext{
${ }^{4}$ The literature on lumpy investment has also considered the possibility of an overhang (or conversely, pent-up demand), driven by past aggregate shocks that can shift the latent distribution of firms' investment imbalances (see Caballero, Engel, Haltiwanger (1995)). Thomas (2002) argued that the lumpiness, and the associated latent investment distribution, does not affect aggregate investment much once the cost of capital is endogenized. House (2014) clarified that this result is driven by the feature of standard neoclassical models - with or without lumpy investment - that the timing of investment is highly elastic with respect to the changes in cost of capital. However, most empirical evidence suggests that investment timing is not so elastic, especially over short and medium horizons (see Caballero (1999)). As House (2014) also notes, "the key property of the model which generates the irrelevance results - the infinite elasticity of investment demand - is a feature of the models and may not be a feature of reality."
} 
tween reallocation and aggregate activity shocks. In our setting, reallocation away from residential investment triggers a Keynesian recession. Moreover, nonresidential investment also declines earlier in the recession, generating sectoral comovement that resembles an aggregate activity shock. Caballero and Hammour (1996) describe a supply-side channel by which reallocation is restricted because the expanding sectors are constrained due to a hold-up problem.

Fourth, we obtain several positive and normative results for investment when the economy features a temporary liquidity trap. These results apply regardless of whether the episode is driven by overbuilding or some other (temporary) demand shock 5 On the positive side, we show that nonresidential investment can decline earlier in the liquidity trap, even if the real interest rate remains low and there are no financial frictions, because low aggregate demand also lowers the return to investment. This mechanism is reminiscent of the acceleration principle of investment that was emphasized in an older literature (see Clark (1917) or Samuelson (1939)), but there are also important differences that we clarify in Section $\left.4.1\right|^{6}$ On the normative side, we show that the private investment decisions during or before a liquidity trap are typically inefficient, and characterize the constrained optimal interventions. These results complement a recent literature that analyzes the inefficiencies driven by aggregate demand externalities. Korinek and Simsek (2014) and Farhi and Werning (2013) focus on ex-ante financial market allocations, such as leverage and insurance, whereas we establish inefficiencies associated with physical investment.7

\section{Basic environment and equilibrium}

The economy is set in infinite discrete time $t \in\{0,1, \ldots\}$ with a single consumption good, and three factors of production: residential capital, $h_{t}$, nonresidential capital, $k_{t}$, and labor, $l_{t}$. For brevity, we also refer to nonresidential capital as "capital." Each

\footnotetext{
${ }^{5} \mathrm{~A}$ growing applied theoretical literature investigates various aspects of the liquidity trap, but often abstracts away from investment for simplicity (see, for instance, Krugman (1998), Eggertsson and Woodford (2003), Auerbach and Obstfeld (2005), Adam and Billi (2006), Jeanne and Svennson (2007), Werning (2012)).

${ }^{6}$ The mechanism is also present in many other New Keynesian models with capital and constrained monetary policy, but it is not always emphasized. In recent work, Schmitt-Grohe and Uribe (2012) also show that the liquidity trap can generate an investment slump driven by low return.

${ }^{7} \mathrm{~A}$ separate literature emphasizes the inefficiencies in physical investment driven by pecuniary externalities (see, for instance, Lorenzoni (2008), Hart and Zingales (2011), Stein (2011), He and Kondor (2014), Davila (2015)).
} 
unit of residential capital produces one unit of housing services. Capital and labor are combined to produce the consumption good according to a neoclassical technology that we describe below.

Absent shocks, the economy converges to a level of residential capital denoted by $h^{*}$, which we refer to as the target level (see Eq. (3) below). We analyze situations in which the economy starts with an initial residential capital that exceeds the target, $h_{0}>h^{*}$, so that an adjustment is necessary.

The assumption, $h_{0}>h^{*}$, can be interpreted in several ways. Our favorite interpretation is that it captures an unmodeled overbuilding episode that took place before the start of our model. In particular, suppose the (expected) housing demand increased in the recent past relative to its historical level. The economy has built residential capital to accommodate this high level of demand, captured by $h_{0}$. At date 0 , the economy receives news that that the high demand conditions are not sustainable. The residential capital stock needs to adjust to its historical average, captured by $h^{*}$. Section 5.2 introduces an ex-ante period and formalizes this interpretation.

An alternative and mathematically equivalent interpretation is that $h_{0}$ corresponds to the historical housing demand, whereas $h^{*}$ represents "the new normal" with permanently low housing demand. One could also imagine intermediate interpretations in which the past overbuilding and the current low demand both play some role in driving the adjustment. We would like to understand how the economy decumulates the excess residential capital.

In our baseline setting, we also abstract away from adjustment costs. In particular, one unit of the consumption good can be converted into one unit of residential or nonresidential capital or vice versa (see Section 4.1 for a version with adjustment costs for residential capital). Thus, the two types of capital evolve according to,

$$
h_{t+1}=h_{t}\left(1-\delta^{h}\right)+i_{t}^{h} \text { and } k_{t+1}=k_{t}\left(1-\delta^{k}\right)+i_{t}^{k} .
$$

Here, $i_{t}^{h}\left(\right.$ resp. $\left.i_{t}^{k}\right)$ denote residential (resp. nonresidential) investment, and $\delta^{h}$ (resp. $\delta^{k}$ ) denotes the depreciation rate for residential (resp. nonresidential) capital.

Households The economy features a representative household with preferences over consumption, labor, and housing services. We assume households' per period utility function takes the following form,

$$
U\left(\hat{c}_{t}, l_{t}, h_{t}\right)=u\left(\hat{c}_{t}-v\left(l_{t}\right)\right)+u^{h} \mathbf{1}\left[h_{t} \geq h^{*}\right] .
$$


Here, the functions $u(\cdot), v(\cdot)$ satisfy the standard regularity conditions. The expression $\mathbf{1}\left[h_{t} \geq h^{*}\right]$ is equal to 1 if $h_{t} \geq h^{*}$ and zero otherwise, and $u^{h}$ is a large constant.

This specification of preferences relies on two simplifying assumptions. First, households always demand the target level of residential capital $h^{*}$, since they receive a large utility from investing up to this level but zero marginal utility from additional units. That is, the household chooses ${ }^{8}$

$$
h_{t+1}=h^{*}, \text { which implies } i_{t}^{h}=h^{*}-h_{t}\left(1-\delta^{h}\right) \text {. }
$$

In particular, starting with some $h_{0}>h^{*}$, the household decumulates its excess residential capital in a single period. Hence, a period in the baseline setting should be thought of as long as necessary (arguably several years) to adjust the housing capital to its steady-state level. This specification is mechanical, but it considerably simplifies the residential investment part of the model, and enables us to focus on the effect of overbuilding on the rest of the equilibrium allocations. Residential investment would qualitatively follow a similar pattern in models with more elastic housing demand.

Second, the functional form $u\left(\hat{c}_{t}-v\left(l_{t}\right)\right)$, implies that the household's labor supply decision does not depend on its consumption (see Greenwood, Hercowitz and Huffman (1988)). Specifically, the optimal labor solves the static problem,

$$
e_{t}=\max _{l_{t}} w_{t} l_{t}-v\left(l_{t}\right)
$$

Here, $e_{t}$ denotes households' net labor income, that is, labor income net of labor costs. We also define $c_{t}=\hat{c}_{t}-v\left(l_{t}\right)$ as net consumption. The household's consumption and saving problem can then be written in terms of net variables as:

$$
\begin{array}{ll} 
& \max _{\left\{c_{t}, a_{t+1}\right\}_{t}} \sum_{t=0}^{\infty} \beta^{t} u\left(c_{t}\right) \\
\text { s.t. } & c_{t}+a_{t+1}+i_{t}^{h}=e_{t}+a_{t}\left(1+r_{t}\right)+\Pi_{t} .
\end{array}
$$

Here, $a_{t}$ denotes her financial assets, $w_{t}$ denotes the wage level, and $\Pi_{t}$ denotes profits received from firms described below, and $i_{t}^{h}$ denotes the optimal level of residential investment characterized by Eq. (3). The optimal household behavior is summarized

\footnotetext{
${ }^{8}$ Residential capital not only provides housing services but it also represents an investment technology. Hence, Eq. (3) also requires the gross interest rate, $1+r_{t+1}$, to be greater than the gross return (on empty houses), $1-\delta^{h}$, which will be the case in equilibrium.
} 
by Eq. (3) and problems (4) and (5).

Investment, the interest rate, and the liquidity trap The capital stock of the economy is managed by a competitive investment sector. This sector equates the interest rate (equivalently, the cost of capital) to the net return to physical capital,

$$
r_{t+1}=R_{t+1}-\delta^{k}
$$

where $R_{t+1}$ denotes the rental rate. The capital market clearing condition is $a_{t}=k_{t}$.

Our key ingredient is that the nominal interest rate is bounded from below. In practice, there might be several reasons why the monetary authority might be unable or unwilling to lower the interest rate below a certain level. We formally consider the zero lower bound constraint, $r_{t+1}^{n} \geq 0$, which appeared to be binding during the Great Recession. This constraint emerges because cash in circulation provides households with transaction services.9 If the nominal interest rate fell below zero, then individuals would switch to hoarding cash instead of holding financial assets. Therefore, monetary policy cannot lower the nominal interest rate (much) below zero. The situation in which the nominal interest rate is at its lower bound is known as the liquidity trap.

The constraint on the nominal interest rate might not affect the real allocations by itself. However, we also assume that nominal prices are completely sticky (as we formalize below) which ensures that the nominal and the real interest rates are the same, and thus the real interest rate is also bounded,

$$
r_{t+1}^{n}=r_{t+1} \geq 0 \text { for each } t
$$

Production firms and output We introduce nominal price rigidities with the standard New Keynesian model. Specifically, there are two types of production firms. A competitive final good sector uses intermediate varieties $\nu \in[0,1]$ to produce the final output according to the Dixit-Stiglitz technology, $\hat{y}_{t}=\left(\int_{0}^{1} \hat{y}_{t}(\nu)^{\frac{\varepsilon-1}{\varepsilon}} d \nu\right)^{\varepsilon /(\varepsilon-1)}$

\footnotetext{
${ }^{9}$ To simplify the notation and the exposition, however, we do not explicitly model cash or its transaction services. We could incorporate these features into the model without changing anything essential. For instance, suppose households' state utility function takes the separable form, $u\left(c_{t}\right)+$ $\varphi\left(m_{t}\right)$, where $m_{t}=M_{t} / P_{t}$ denotes households' real money balances and $\varphi(\cdot)$ is an increase and concave function with $\varphi^{\prime}(\bar{m})=0$ for some $\bar{m}$. With this specification, the non-monetary equilibrium allocations remain unchanged. The equilibrium money balances are obtained by solving $\varphi^{\prime}\left(m_{t}\right)=$ $\frac{r_{t+1}^{n}}{1+r_{t+1}^{n}} u^{\prime}\left(c_{t}\right)$ for each $t$, given the equilibrium levels of the nominal interest rate, $r_{t+1}^{n}$, and net consumption, $c_{t}$.
} 
where $\varepsilon>1$. In turn, a unit mass of monopolistic firms labeled by $\nu \in[0,1]$ each produces the variety according to, $\hat{y}_{t}(\nu)=F\left(k_{t}(\nu), l_{t}(\nu)\right)$, where $F(\cdot)$ is a neoclassical production function with standard regularity conditions.

We make the extreme assumption that each monopolist has a preset and constant nominal price, $P_{t}(\nu)=P$ for each $\nu$. This also implies that monopolists are symmetric: they face the same real price (equal to one) and they choose the same level of inputs and outputs subject to an aggregate demand constraint. In particular, the representative monopolist's problem can be written as:

$$
\Pi_{t}=\max _{k_{t}, l_{t}} F\left(k_{t}, l_{t}\right)-w_{t} l_{t}-R_{t} k_{t} \text { s.t. } F\left(k_{t}, l_{t}\right) \leq \hat{y}_{t}
$$

In the equilibria we will analyze, the monopolist's marginal cost will be below its price so that it will find it optimal to meet all of its demand. Thus, the output satisfies $\hat{y}_{t}=F\left(k_{t}, l_{t}\right)$. In view of GHH preferences, we find it more convenient to work with the net output, that is, output net of labor costs, $y_{t}=\hat{y}_{t}-v\left(l_{t}\right)$. The net output is determined by the net aggregate demand, $y_{t}=c_{t}+i_{t}^{k}+i_{t}^{k}$, which also depends on the monetary policy.

Efficient benchmark and the monetary policy Since the price level is fixed, we assume that the monetary policy focuses on replicating the efficient allocations ${ }^{10}$ Given date $t$ with state variables $k_{t}, h_{t} \geq h^{*}$, the efficient benchmark is the continuation allocation that maximizes households' welfare subject to the feasibility constraints. Appendix B shows that the efficient benchmark solves,

$$
\begin{aligned}
V\left(k_{t}, h_{t}\right) & =\max _{\left\{c_{\tilde{t}}, k_{\tilde{t}+1}\right\}_{\tilde{t}=t}^{\infty}} \sum_{\tilde{t}=t}^{\infty} \beta^{\tilde{t}} u\left(c_{\tilde{t}}\right), \\
\text { s.t. } & c_{\tilde{t}}+k_{\tilde{t}+1}-\left(1-\delta^{k}\right) k_{\tilde{t}}+i_{\tilde{t}}^{h}=s\left(k_{\tilde{t}}\right) .
\end{aligned}
$$

Here, $i_{\tilde{t}}^{h}$ is given by Eq. (3), and the function $s(\cdot)$ is defined as,

$$
s\left(k_{t}\right)=F\left(k_{t}, l_{t}^{*}\right)-v\left(l_{t}^{*}\right), \text { where } l_{t}^{*} \in \arg \max _{\tilde{l}} F\left(k_{t}, \tilde{l}\right)-v(\tilde{l}) .
$$

\footnotetext{
${ }^{10}$ In particular, the monetary policy does not replicate the "frictionless" equilibrium that would obtain if monopolists could reset their prices at every period. Instead, the monetary policy also corrects for the distortions that would stem from the monopoly pricing. Ideally, these distortions should be corrected by other policies, e.g., monopoly subsidies, and the monetary policy should focus on replicating the frictionless benchmark. We ignore this distinction so as to simplify the notation.
} 
Note that the efficient benchmark maximizes the net output in every period. We refer to $y_{t}^{*}=s\left(k_{t}\right)$ as the efficient (or supply determined) level of net output, and $l_{t}^{*}$ as the efficient level of employment. The efficient dynamic allocations are found by solving a standard neoclassical planning problem ${ }^{11}$

Given the efficient benchmark, the monetary policy follows the interest rate rule,

$$
r_{t+1}^{n}=r_{t+1}=\max \left(0, r_{t+1}^{*}\right) \text { for each } t \geq 0 .
$$

Here, $r_{t+1}^{*}$ is recursively defined as the natural interest rate that obtains when employment and net output at date $t$ are at their efficient levels in (10), and the monetary policy follows the rule in (11) at all future dates ${ }^{12}$ In particular, the monetary policy replicates the statically efficient allocations subject to the zero lower bound constraint. This policy is constrained efficient in our environment as long as the monetary policy does not have commitment power.

Definition 1. The equilibrium is a path of allocations, $\left\{h_{t}, k_{t}, l_{t}, \hat{c}_{t}, c_{t}, i_{t}^{h}, i_{t}^{k}, \hat{y}_{t}, y_{t}\right\}_{t}$, and real prices and profits, $\left\{w_{t}, R_{t}, r_{t+1}, \Pi_{t}\right\}_{t}$, such that the households and firms choose allocations optimally as described above, the interest rate is set according to (11), and all markets clear.

\section{Investment hangover and the recession}

We next turn to the characterization of equilibrium. The following lemma establishes the basic properties of the equilibrium within a period.

Lemma 1. (i) If $r_{t+1}>0$, then $y_{t}=s\left(k_{t}\right), l_{t}=l_{t}^{*}$, and $R_{t}=s^{\prime}\left(k_{t}\right)$.

(ii) If $r_{t+1}=0$, then the net output is below the efficient level, $y_{t} \leq s\left(k_{t}\right)$, and is determined by net aggregate demand, $y_{t}=c_{t}+i_{t}^{k}+i_{t}^{h}$. The labor supply is below its efficient level, $l_{t} \leq l_{t}^{*}$, and is determined as the unique solution to,

$$
y_{t}=F\left(k_{t}, l_{t}\right)-v\left(l_{t}\right) \text { over the range } l_{t} \in\left[0, l_{t}^{*}\right] .
$$

\footnotetext{
${ }^{11}$ To ensure an interior solution, we assume the parameters are such that the economy is able to afford the required residential investment at all dates. A sufficient condition is $\min \left(s\left(k_{0}\right), s\left(k^{*}\right)\right)>$ $\delta^{k} k^{*}+\delta h^{*}$.

${ }^{12}$ Equivalently, we coulud also take $r_{t+1}^{*}$ to be the interest rate that obtains in the first best benchmark characterized in problem (9). In our baseline setting, these two definitions are the same since the zero lower bound constraint does not bind from date 1 onwards. Our recursive definition is more appropriate (although slightly more complicated) in environments in which the constraint can also bind in future dates.
} 
The rental rate of capital is given by $R_{t}=R\left(k_{t}, y_{t}\right) \leq s^{\prime}\left(k_{t}\right)$, where the function $R\left(k_{t}, y_{t}\right)$ is strictly decreasing in $k_{t}$ and strictly increasing in $y_{t}$.

Part (i) describes the case in which the interest rate is positive and the monetary policy replicates the efficient outcomes. Part (ii) describes the liquidity trap scenario in which the interest rate is at its lower bound. In this case, the economy experiences a recession with low net output and employment.

Lemma 1 also characterizes the rental rate of capital in each case, which determines the return to investment. To understand these results, consider monopolists' factor demands, captured by the optimality conditions for problem (8),

$$
\left(1-\tau_{t}\right) F_{k}\left(k_{t}, l_{t}\right)=R_{t} \text { and }\left(1-\tau_{t}\right) F_{l}\left(k_{t}, l_{t}\right)=w_{t} .
$$

Here, $\tau_{t} \geq 0$ denotes the Lagrange multiplier on the demand constraint in (8), which is also the labor wedge in this model. If the interest rate is positive, then employment is at its efficient level and the labor wedge is zero, $\tau_{t}=0$. In this case, the demand constraint effectively does not bind and the factors earn their marginal products. If instead the interest rate is zero, then the employment is below its efficient level and the labor wedge is positive, $\tau_{t}>0$. In this case, the demand shortage lowers capital's (as well as labor's) rental rate relative to the efficient benchmark. The second part of the lemma shows further that the return to capital in this case can be written as a function of the capital stock and net output. Greater $k_{t}$ reduces the rental rate due to diminishing returns, whereas greater $y_{t}$ increases it due to greater demand.

Lemma 1 implies further that the capital stock is bounded from above,

$$
k_{t+1} \leq \bar{k} \text { for each } t \text {, where } s^{\prime}(\bar{k})-\delta^{k}=0 .
$$

Here, the upper bound $\bar{k}$ is the level of capital that delivers a net return of zero absent a demand shortage. Investing beyond this level would never be profitable given the lower bound to the cost of capital in (7), as well as the possibility of a demand shortage. This bound will play a central role in the subsequent analysis.

\subsection{Investment hangover}

We next characterize the dynamic equilibrium under the assumption that the economy starts with too much residential capital,

$$
h_{0}=\left(1+b_{0}\right) h^{*}, \text { where } b_{0}>0 .
$$


Here, $b_{0}$ parameterizes the degree of past overbuilding. Eq. (3) then implies,

$$
i_{0}^{h}=h^{*}-\left(1-\delta^{h}\right) h_{0}=\left(\delta^{h}-b_{0}\left(1-\delta^{h}\right)\right) h^{*} .
$$

Note that the residential investment at date 0 is below the level required to maintain the target, $i_{0}^{h}<\delta^{h} h^{*}$. Thus, overbuilding represents a negative shock to the residential investment demand. The equilibrium depends on how the remaining components of aggregate demand, $i_{0}^{k}$ and $c_{0}$, respond to this shock.

To characterize this response, we solve the equilibrium backwards. Suppose the economy reaches date 1 with $h_{1}=h^{*}$ and some capital level $k_{1} \leq \bar{k}$. Since the residential capital has already adjusted, the continuation equilibrium does not feature a liquidity trap, that is, $r_{t+1}>0$ for each $t \geq 1$. Consequently, monetary policy replicates the efficient benchmark starting date 1 . The equilibrium is the solution to problem (9) given $h_{1}=\bar{h}$ and $k_{1} \leq \bar{k}$. The appendix shows that the solution converges to a steady-state $\left(c^{*}, k^{*}\right)$, characterized by

$$
s^{\prime}\left(k^{*}\right)-\delta^{k}=1 / \beta-1 \text { and } c^{*}=s\left(k^{*}\right)-\delta^{k} k^{*}-\delta^{h} h^{*} .
$$

The initial consumption is given by $c_{1}=C\left(k_{1}\right)$, for an increasing function $C(\cdot)$.

Next consider the equilibrium at date 0 . The key observation is that both nonresidential investment and consumption are bounded from above due to the lower bound on the interest rate. In particular, the bound on capital in Eq. (14) also implies,

$$
i_{1}^{k} \leq \bar{k}-\left(1-\delta^{k}\right) k_{0} .
$$

Intuitively, only so many investment projects can be undertaken without violating the lower bound on the safe (or more broadly, risk adjusted) cost of capital. Likewise, consumption is bounded by the Euler equation at the zero interest rate,

$$
c_{0} \leq \bar{c}_{0}, \text { where } u^{\prime}\left(\bar{c}_{0}\right)=\beta u^{\prime}(C(\bar{k})) .
$$

Intuitively, the household can only be induced to consume so much without violating the lower bound on the interest rate.

Combining the bounds in (14) and (18) with the demand shock in (16), the aggregate demand (and output) at date 0 is also bounded from above, that is,

$$
y_{0} \leq \bar{y}_{0} \equiv \bar{k}-\left(1-\delta^{k}\right) k_{0}+\bar{c}_{0}+\left(\delta^{h}-b_{0}\left(1-\delta^{h}\right)\right) h^{*} .
$$


The equilibrium depends on the comparison between the maximum demand and the efficient level, i.e., whether $\bar{y}_{0}<s\left(k_{0}\right)$. This in turn depends on whether the amount of overbuilding $b_{0}$ exceeds a threshold level,

$$
\bar{b}_{0} \equiv \frac{\bar{k}-\left(1-\delta^{k}\right) k_{0}+\bar{c}_{0}+\delta^{h} h^{*}-s\left(k_{0}\right)}{\left(1-\delta^{h}\right) h^{*}} .
$$

Proposition 1 (Overbuilding and the Liquidity Trap). Suppose $b_{0}>0$.

(i) If $b_{0} \leq \bar{b}_{0}$, then, the date 0 equilibrium features,

$$
r_{1} \geq 0, y_{0}=s\left(k_{0}\right) \text { and } l_{0}=l_{0}^{*}
$$

(ii) If $b_{0}>\bar{b}_{0}$, then, the date 0 equilibrium features a liquidity trap with,

$$
r_{1}=0, k_{1}=\bar{k}, y_{0}=\bar{y}_{0}<s\left(k_{0}\right) \text { and } l_{0}<l_{0}^{*}
$$

Moreover, the net output $y_{0}$ and the labor supply $l_{0}$ are decreasing in $b_{0}$.

In either case, starting at date 1 , the economy converges to a steady state $\left(k^{*}, c^{*}\right)$.

Part (i) describes the equilibrium for the case in which the initial overbuilding is not too large. In this case, the economy does not fall into a liquidity trap. Residential disinvestment is offset by a reduction in the interest rate and an increase in nonresidential investment and consumption, leaving the output and employment determined by productivity. The left part of the panels in Figure 3 (the range corresponding to $\left.b_{0} \leq \bar{b}_{0}\right)$ illustrate this outcome. This is the Austrian case.

Part (ii) of Proposition 1, our main result, characterizes the case in which the initial overbuilding is sufficiently large. In this case, the demand shock associated with residential disinvestment is large enough to plunge the economy into a liquidity trap. The lower bound on the interest rate prevents the nonresidential investment and consumption from expanding sufficiently to pick up the slack aggregate demand. As a consequence, the initial shock translates into a Keynesian recession with low output and employment. Figure 3 illustrates this result. Greater overbuilding triggers a deeper recession. This is the Keynesian case of our model.

\subsection{Comparative statics of the liquidity trap}

We next investigate the conditions under which a given amount of overbuilding $b_{0}$ triggers a liquidity trap. As illustrated by Eq. (20), factors that reduce aggregate demand at date 0 , such as a higher discount factor $\beta$ (that lowers $\bar{c}_{0}$ ), increase the 
Residential investment, $i_{0}^{h}$

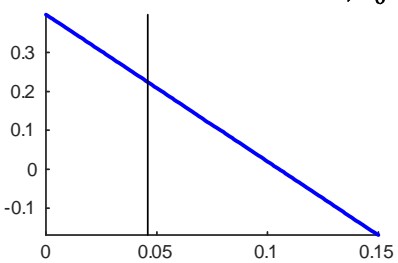

Interest rate (percent), $r_{1}$

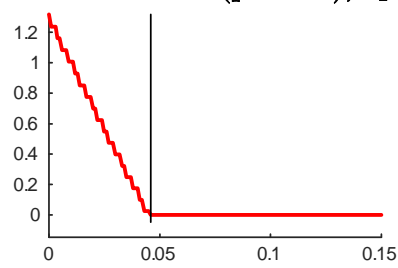

Net consumption, $c_{0}$

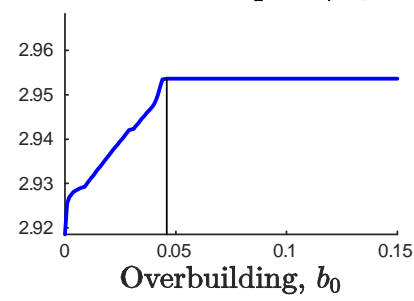

Nonres capital, $k_{1}$

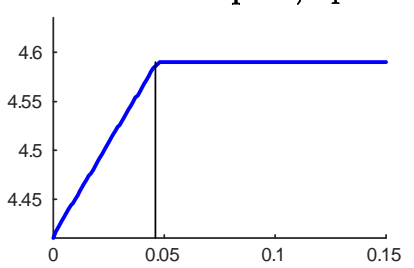

Net output, $y_{0}$
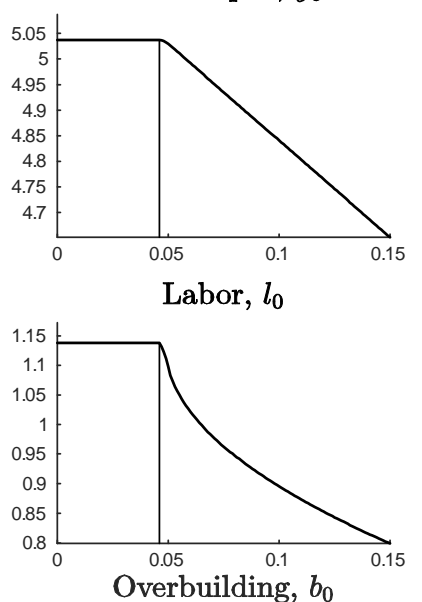

Nonres investment, $i_{0}^{k}$

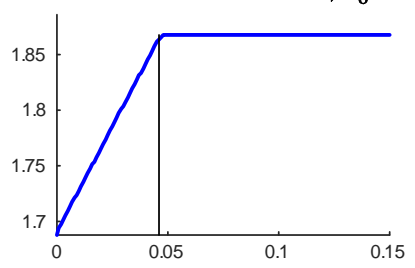

Actual output

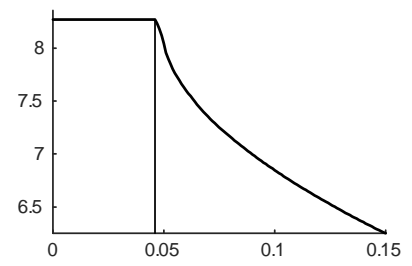

Labor wedge, $\tau_{0}$

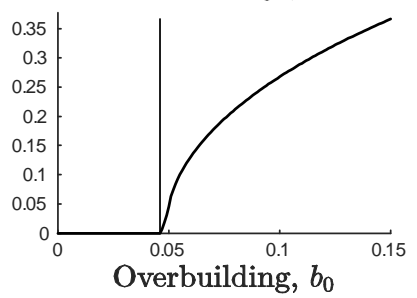

Figure 3: Date 0 equilibrium variables as a function of the initial overbuilding $b_{0}$ (measured as a fraction of the target residential capital stock, $h^{*}$ ). 
incidence of the liquidity trap in our setting. More generally, other frictions that reduce aggregate demand during the decumulation phase, such as household deleveraging or the financial crisis, are also complementary to our mechanism. Intuitively, this is because the liquidity trap represents a nonlinear constraint on the interest rate. In particular, a demand shock that lowers the interest rate leaves a smaller slack for monetary policy, increasing the potency of other demand shocks such as overbuilding.

Eq. (20) illustrates that a higher initial level of nonresidential capital stock $k_{0}$ also increases the incidence of a liquidity trap. A higher $k_{0}$ affects the equilibrium at date 0 through two main channels. First, a higher $k_{0}$ reduces nonresidential investment at date 0 and lowers aggregate demand. Second, a higher $k_{0}$ also increases the efficient output, $s\left(k_{0}\right)$, which makes it more likely that the economy will have a demand shortage. Overbuilding of the two types of capital is complementary in terms of triggering a liquidity trap.

A distinguishing feature of residential capital is its high durability relative to many other types of capital. We next investigate whether high durability is conducive to triggering a liquidity trap. To isolate the effect of durability, consider a slight variant of the model in which there are two types of residential capital that mainly differ in terms of durability. Specifically, the two types depreciate at different rates given by $\delta^{h^{d}}$ and $\delta^{h^{n}}$, with $\delta^{h^{d}}<\delta^{h^{n}}$. Thus, type $d$ (durable) residential capital has a lower depreciation rate than type $n$ (nondurable) residential capital. Suppose the preferences in (2) are modified so that each type has a target level $h^{*} / 2$. Suppose also that $\left(\delta^{h^{d}}+\delta^{h^{n}}\right) / 2=\delta^{h}$ so that the average depreciation rate is the same as before. Let $h_{0}^{d}=\left(1+b_{0}^{d}\right)\left(h^{*} / 2\right)$ and $h_{0}^{n}=\left(1+b_{0}^{n}\right)\left(h^{*} / 2\right)$, so that $b_{0}^{d}$ and $b_{0}^{n}$ capture the overbuilding in respectively durable and nondurable capital. The case with symmetric overbuilding, $b_{0}^{d}=b_{0}^{n}=b_{0}$, results in the same equilibrium as in the earlier model. Our next result investigates the effect of overbuilding one type of capital more than the other.

Proposition 2 (Role of Durability). Consider the model with two types of residential capital with different depreciation rates. Given the average overbuilding $b_{0}=\left(b_{0}^{d}+b_{0}^{n}\right) / 2$, the incidence of a liquidity trap $1\left[l_{0}<l_{0}^{*}\right]$ is increasing in overbuilding of the more durable residential capital $b_{0}^{d}$.

To obtain an intuition, consider the maximum aggregate demand at date 0 , which can be written as [cf. Eq. (19)],

$$
\bar{y}_{0}=\bar{k}-\left(1-\delta^{k}\right) k_{0}+\bar{c}_{0}+\delta^{h} h^{*}-b_{0}^{d}\left(1-\delta^{h^{d}}\right) \frac{h^{*}}{2}-b_{0}^{n}\left(1-\delta^{h^{n}}\right) \frac{h^{*}}{2} .
$$




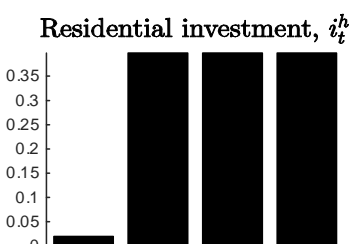

Interest rate (percent), $r_{t+1}$

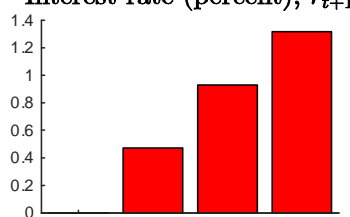

Net consumption, $c_{t}$

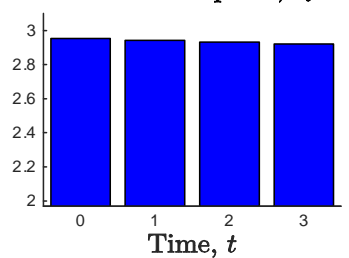

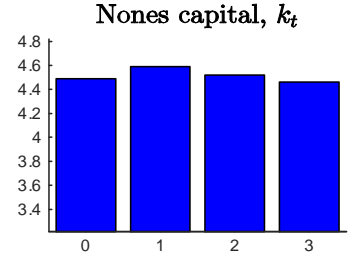

Net output, $y_{t}$

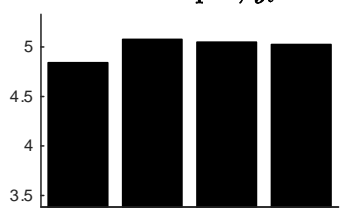

Labor, $l_{t}$

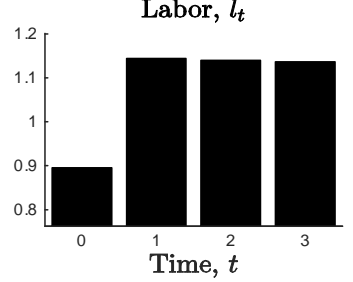

Nonres investment, $i_{t}^{k}$

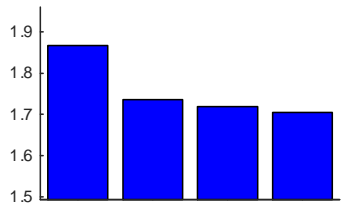

Actual output

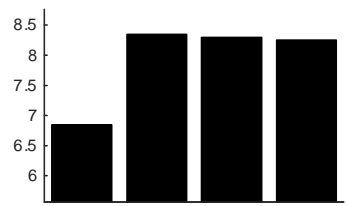

Labor wedge, $\tau_{t}$

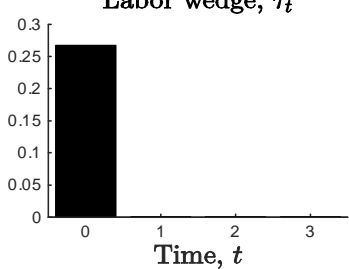

Figure 4: The evolution of equilibrium variables over time, starting with $b_{0}>\bar{b}_{0}$.

Note that $1-\delta^{h^{d}}>1-\delta^{h^{n}}$, and thus, overbuilding of the durable residential capital (relative to the nondurable capital) induces a greater reduction in aggregate demand at date 0 . Intuitively, depreciation helps to "erase" the overbuilt capital naturally, thereby inducing a smaller reduction in investment.

This result suggests that overbuilding is a greater concern when it hits durable capital such as residential investment, structures, or infrastructure (e.g., railroads), as opposed to less durable capital such as equipment or machinery. A previous literature has empirically investigated whether the overbuilding of information technology (IT) equipment during the boom years of late 1990s and 2000 might have contributed to the 2001 recession in the US (see Desai and Goolsbee (2004) and the references therein). Note, however, that the IT equipment such as computers tend to depreciate very quickly. A more fruitful research direction could be to empirically investigate episodes that feature overbuilding of more durable types of capital.

\subsection{Aftermath of the recession}

We next investigate the equilibrium behavior in the aftermath of the liquidity trap. Figure 4 plots the full dynamic equilibrium in the original model with single residential capital (and in the liquidity trap scenario). The initial shock generates a temporary 


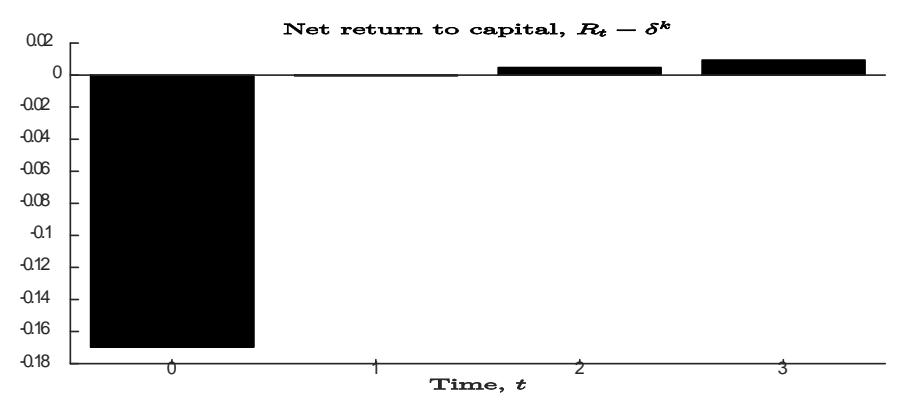

Figure 5: The evolution of net return to capital over time, starting with $b_{0}>\bar{b}_{0}$.

recession, followed by a neoclassical adjustment after the recession.

The interest rate gradually increases during the aftermath of the recession, and might remain below its steady-state level for several periods. This is because the economy accumulates capital during the liquidity trap thanks to low interest rates. The economy decumulates this capital only gradually over time, which leaves the rate of return low after the recession. These low rates are reminiscent of the secular stagnation hypothesis, recently revived by Summers (2013). According to this hypothesis, the economy could permanently remain depressed with low interest rates due to a chronic demand shortage (see Eggertsson and Mehrotra (2014) for a formalization). In our model, the economy eventually recovers. But the low rates in the aftermath suggest that the economy remains fragile to another demand shock. Intuitively, the economy has used much of its investment capacity to fight the reduction of demand at date 0 , which leaves little capacity to fight another demand shock going forward.

Figure 4 illustrates further that, while there is a recession at date 0, several components of aggregate demand - especially nonresidential investment - actually expand. The recession is confined to the residential investment sector in which the shock originates. This prediction is inconsistent with facts in major recessions, such as the Great Recession, in which all components of aggregate demand decline simultaneously. To address this puzzle, we next analyze the investment response in more detail.

\section{Investment response and the accelerator}

This section investigates a variant of the model in which the liquidity trap persists over multiple periods. We show how the overbuilding of residential capital can induce an initial bust in nonresidential investment followed by a boom. We also discuss the relationship of our model to the acceleration principle of investment. We finally 
briefly discuss how our model can be further extended to generate an initial reduction in consumption.

The analysis is motivated by Figure 5, which illustrates the evolution of the net return to capital $R_{t}-\delta^{k}$ corresponding to the equilibrium plotted in Figure 4. The near-zero return during the recovery phase reflects the high level of accumulated capital. The figure illustrates that the net return at date 0 , given the predetermined capital stock $k_{0}$, is even lower. Intuitively, the recession at date 0 lowers not only the output but also factor returns, including the return on capital (see Lemma 1). This suggests that, if nonresidential investment could respond to the shock during period 0 , it could also fall.

To investigate this possibility, we modify the model so that the residential disinvestment is spread over many periods. One way to ensure this is to assume that there is a lower bound on housing investment at every period.

Assumption 1. $i_{t}^{h} \geq i^{h}$ for each $t$, for some $i^{h}<\delta^{h} h^{*}$.

For instance, the special case $i^{h}=0$ captures the irreversibility of housing investment. More generally, the lower bound provides a tractable model of adjustment costs. To simplify the exposition, we also assume that the initial housing capital, $h_{0}=$ $h^{*}\left(1+b_{0}\right)$, is such that the economy adjusts to the target level in exactly $T \geq 1$ periods.

Assumption 2. $\delta^{h} h^{*}=\left(\delta^{h} h_{0}\right)\left(1-\delta^{h}\right)^{T}+i^{h}\left(1-\left(1-\delta^{h}\right)^{T}\right)$ for an integer $T \geq 1$.

With these assumptions, the residential investment path is given by

$$
i_{t}^{h}=\left\{\begin{array}{cc}
i^{h}<\delta^{h} h^{*} & \text { if } t \in\{0, \ldots, T-1\} \\
\delta^{h} h^{*} & \text { if } t \geq T
\end{array},\right.
$$

For future reference, note that the parameter $i^{h}$ also provides an (inverse) measure of the severity of the residential investment shock.

As before, we characterize the equilibrium backwards. The economy reaches date $T$ with residential capital $h_{T}=h^{*}$ and some $k_{T} \leq \bar{k}$. The continuation equilibrium is characterized by solving problem (9) as before. In particular, consumption is given by $c_{T}=C\left(k_{T}\right)$, where recall that $C(\cdot)$ is an increasing function.

Next consider the equilibrium during the decumulation phase, $t \in\{0, . ., T-1\}$. We conjecture that - under appropriate assumptions - there is an equilibrium that features a liquidity trap at all of these dates, that is, $r_{t+1}=0$ for each $t \in\{0, . ., T-1\}$. In this equilibrium, the economy reaches date $T$ with the maximum level of capital, 
$k_{T}=\bar{k}$ (since $r_{T}=0$ ). Consumption is also equal to its maximum level, that is, $c_{t}=\bar{c}_{t}$ for each $t$, where

$$
u^{\prime}\left(\bar{c}_{t}\right)=\beta u^{\prime}\left(\bar{c}_{t+1}\right) \text { for each } t \in\{0,1, . ., T-1\} .
$$

It remains to characterize the path of the capital stock $\left\{k_{t}\right\}_{t=1}^{T-1}$ during the decumulation phase.

To this end, consider the investment decision at some date $t-1$, which determines the capital stock at date $t$. The net return from this investment is given by $R\left(k_{t}, y_{t}\right)-$ $\delta^{k}$ (cf. Lemma 1). The net cost of investment is given by $r_{t}=0$. The economy invests at date $t-1$ up to the point at which the benefits and costs are equated,

$$
R\left(k_{t}, y_{t}\right)-\delta^{k}=0 \text { for each } t \in\{1, . ., T-1\}
$$

Recall that the return function $R(\cdot)$ is decreasing in the capital stock $k_{t}$ and increasing in net output $y_{t}$. Hence, Eq. (23) says that, if the (expected) output at date $t$ is large, then the economy invests more at date $t-1$ and obtains a greater capital stock at date $t$.

The level of output is in turn determined by the aggregate demand at date $t$,

$$
y_{t}=\bar{c}_{t}+k_{t+1}-\left(1-\delta^{k}\right) k_{t}+i^{h} \text { for each } t \in\{0, \ldots, T-1\} \text {. }
$$

Eqs. (23) and (24) represent a difference equation that can be solved backwards starting with $k_{T}=\bar{k}$. The resulting path corresponds to an equilibrium as long as $s\left(k_{0}\right)>y_{0}$, so that there is a liquidity trap in the first period as we have conjectured. The next result establishes that this is the case if the shock is sufficiently severe, as captured by low $i^{h}$, and characterizes the behavior of nonresidential capital in equilibrium ${ }^{13}$

Proposition 3 (Nonresidential Investment Response). Consider the model with the adjustment length $T \geq 2$. Suppose Assumptions 1-2 and Assumption 3 in Appendix $B$ hold 14

(i) There exists $i^{h, 1}$ such that if $i^{h}<i^{h, 1}$, then there is a unique equilibrium path

\footnotetext{
${ }^{13}$ If the condition $i^{h}<i_{1}^{h}$ is violated, then there is an alternative equilibrium in which there is a partial liquidity trap at dates $t \in\left\{T_{b}-1, . ., T-1\right\}$ for some $T_{b} \geq 2$. We omit the characterization of these equilibria for brevity.

${ }^{14}$ Assumption 3 is a regularity condition on shocks and parameters that ensures an interior liquidity trap equilibrium at date 0 with positive output. This assumption is satisfied for all of our numerical simulations and is relegated to the appendix for brevity.
} 
$\left\{k_{t}, y_{t-1}\right\}_{t=1}^{T}$, which solves Eqs. 23 - 24 along with $k_{T}=\bar{k}$. The equilibrium features a liquidity trap at each date $t \in\{0, . ., T-1\}$ with $r_{t+1}=0$ and $y_{t}<s\left(k_{t}\right)$.

(ii) There exists $i^{h, 2} \leq i^{h, 1}$ such that, if $i^{h}<i^{h, 2}$, then the nonresidential capital declines at date 1 , and then increases before date $T$ :

$$
k_{0}>k_{1} \text { and } k_{1}<k_{T}=\bar{k} \text {. }
$$

The main result of this section is the second part, which establishes conditions under which the nonresidential capital (and investment) follow a non-monotone path during the recession: falling initially, but eventually increasing.

To understand the drop in investment, note that a negative shock to residential investment reduces aggregate demand and output. This in turn lowers nonresidential investment as captured by the break-even condition (23). When the shock is sufficiently severe, the aggregate demand at date 1 is sufficiently low that capital declines. Intuitively, the economy is optimally responding to the low return to capital depicted in Figure 5 .

In later periods, aggregate demand and output gradually increase in anticipation of the eventual recovery. As this happens, the low cost of capital becomes the dominant factor for nonresidential investment. Consequently, the economy starts reaccumulating capital, and in fact - exits the liquidity trap with the maximum level of capital $\bar{k}$ as in the earlier model.

Figure 6 illustrates the dynamic evolution of the equilibrium variables for the case $T=2$. The parameters are chosen so that the figure can be compared to Figure 4 after replacing a single period with two periods. The lower panels on the left illustrate the non-monotonic response of capital and investment identified in Proposition 3. The figure illustrates that the recession can be roughly divided into two phases. In the first phase, captured by date 0 , both types of investment fall. This induces a particularly severe recession with low output and employment. In the second phase, captured by date 1 in the figure (and dates $t \in\{1, . ., T-1\}$ more generally), residential investment remains low whereas the nonresidential investment gradually recovers and eventually booms. The nonresidential investment response also raises aggregate demand. Hence, the second phase of the recession in our model represents a partial and asymmetric recovery in which the residential sector is left behind, similar to the aftermath of the Great Recession (see Figure 1). 

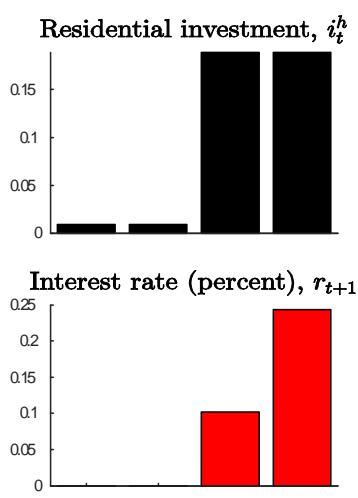

Net consumption, $c_{t}$

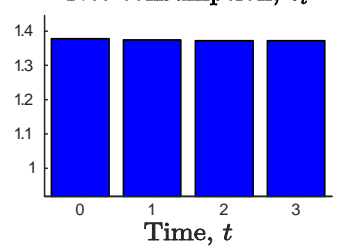

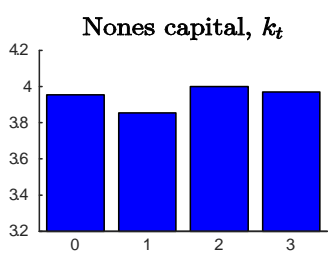

Net output, $y_{t}$

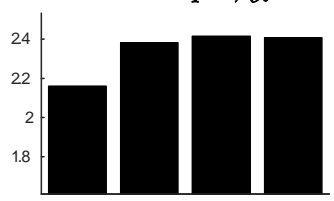

Labor, $l_{t}$

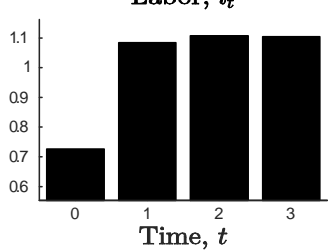

Nonres investment, $i_{t}^{k}$

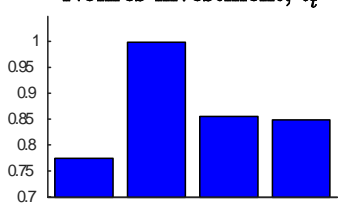

Actual output

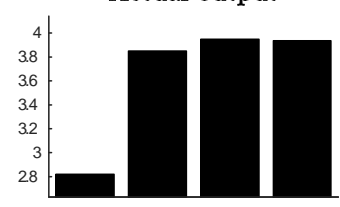

Labor wedge, $\tau_{t}$

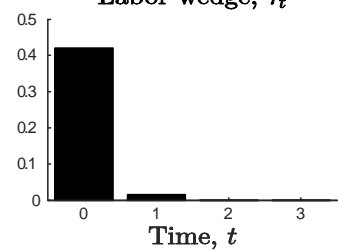

Figure 6: The evolution of equilibrium variables over time, given the length of decumulation $T=2$.

\subsection{Comparison with the acceleration principle}

Our analysis of nonresidential investment bears a certain resemblance with the accelerator theory of investment (see Clark (1917)). To illustrate the similarities, let us linearize Eq. (23) around $(k, y) \simeq(\bar{k}, s(\bar{k}))$, to obtain the approximation

$$
k_{t} \simeq \alpha+\beta E_{t-1}\left[y_{t}\right] \text { for each } t \in\{1, . ., T-1\},
$$

where $\beta=-R_{y} / R_{k}>0, \alpha=\bar{k}-\beta s(\bar{k})$, and $E_{t-1}\left[y_{t}\right]=y_{t}$. We introduce the (redundant) expectations operator to compare our rational expectations approach with the previous literature. Taking the first differences of this expression, and assuming that the depreciation rate is small, $\delta^{k} \simeq 0$, we further obtain

$$
i_{t}^{k} \simeq k_{t+1}-k_{t} \simeq \beta\left(y_{t+1}-y_{t}\right) \text { for each } t \in\{1, . ., T-2\} .
$$

Starting at date 1, our model implies a version of the acceleration principle, which posits that investment is proportional to changes in output (see Eckaus (1953) for a review).

Our model, however, has several important differences. First, the accelerator theory posits a relationship between the investment flow and the changes in output 
(or consumption) flows, without explicitly keeping track of the capital stock. In contrast, the capital stock plays an important role in our analysis. In fact, our main point is that a high level of the initial capital stock reduces aggregate demand. To see this, consider the analog of Eq. (25) for date 0,

$$
i_{0}^{k} \simeq k_{1}-k_{0} \simeq \alpha+\beta y_{1}-k_{0}
$$

Similar to Eq. 25), a reduction in expected output, $y_{1}$, or an increase in the initial capital stock, $k_{0}$, reduces investment. However, unlike Eq. (25), the initial stock, $k_{0}$, is a given of the model and is not necessarily related to the initial output, $y_{0}$. In fact, Eq. (19) shows that these two variables are inversely related. This is because an increase in the initial stock of capital reduces aggregate demand via the investment hangover mechanism. Our analysis, thus, suggests that the acceleration principle should be qualified for the early stages of demand-driven recessions (or booms) in which the initial capital stock might be inappropriate for the current level of economic activity.

A second difference is that the relationship in (25) is mechanically assumed in the accelerator literature, whereas we obtain Eq. $(23)$ by combining the optimal investment behavior with the liquidity trap. In particular, our analysis suggests that the liquidity trap (or constrained monetary policy) is important for obtaining strong accelerator effects. Otherwise, the interest rate response would also affect investment. Moreover, the interest rate would typically respond in a way to dampen the accelerator effects (e.g., if the monetary policy focuses on output stabilization) 15

A third difference is that the agents in our economy hold rational expectations, whereas the macroeconomic applications of the accelerator theory often use versions of Eq. (25) with backward looking expectations (for instance, $E_{t-1}\left[y_{t}\right]=y_{t-2}$ ). In particular, our model does not feature the periodic oscillations of output emphasized in Samuelson (1939) or Metzler (1941), which are driven by adaptive expectations.

\subsection{Consumption response}

While our model can account for the decline in investment in the earlier part of the recession, it cannot generate a similar behavior for consumption. As Figure 6 illus-

\footnotetext{
${ }^{15}$ In his review of the accelerator theory, Caballero (1999) notes: "the absence of prices (the cost of capital, in particular) from the right-hand side of the flexible accelerator equation has earned it disrespect despite its empirical success." The liquidity trap provides a theoretical rationale for excluding the cost of capital from the investment equation.
} 
trates, (net) consumption expands during the recession due to the Euler equation ${ }^{16}$ However, the Euler equation - and the permanent income hypothesis that it implies cannot fully capture the behavior of consumption in response to income changes in the data. After reviewing the vast empirical literature on this topic, Jappelli and Pistaferri (2010) note "there is by now considerable evidence that consumption appears to respond to anticipated income increases, over and above by what is implied by standard models of consumption smoothing."

To make consumption more responsive to income, Appendix A.1 extends the model by introducing additional households that have high marginal propensities to consume (MPC) out of income. The main result shows that, if there are sufficiently many high-MPC households, then aggregate consumption initially declines. Intuitively, the low output earlier in the recession lowers all households' incomes, which in turn reduces aggregate consumption due to the high-MPC households. As output increases later in the recession, so does consumption. Hence, consumption also responds non-monotonically to overbuilding.

The appendix also shows that the model with high-MPC households features a Keynesian income multiplier with two implications. First, the recession is more severe than in the baseline model, because the decline of consumption exacerbates the reduction in aggregate demand and output. Second, the accelerator effects are more pronounced in the sense that investment decreases more early in the recession, while also increasing more later in the recession. In this sense, the multiplier and the accelerator effects reinforce one another.

\section{$5 \quad$ Policy implications}

We next investigate the welfare implications of our analysis. Since our model features a liquidity trap, several policies that have been discussed in the literature are also relevant in this context. ${ }^{17}$ We skip a detailed analysis of these policies for brevity. Instead, we focus on constrained policy interventions directed towards controlling investment (residential and nonresidential), which plays the central role in our analysis.

\footnotetext{
${ }^{16}$ Actual consumption, $c_{t}=\hat{c}_{t}+v\left(l_{t}\right)$, might fall in view of the reduction in employment, $l_{t}$. We do not emphaisze this result since it is mainly driven by the GHH functional form for the preferences, which we adopted for expositional simplicity.

${ }^{17}$ In particular, welfare can be improved with unconventional monetary policies as in Eggertsson and Woodford (2003), or unconventional tax policies as in Correia et al. (2013). Once we modify the model appropriately to include government spending, welfare can also be improved by increasing government spending during the recession as in Werning (2012) and Christiano et al. (2011).
} 
We first discuss ex-post policies by which the government can improve welfare once the overbuilding is realized. We then discuss ex-ante policies that the government can implement (prior to date 0) as a precaution.

The policy implications are driven by aggregate demand externalities, which are best illustrated by Figure 3 in the baseline setting. In the region, $b_{0} \geq \bar{b}_{0}$, increasing the initial stock of housing, $b_{0}$, does not change the initial net consumption, $c_{0}$, which is a sufficient statistic for welfare (because it also takes into account labor costs). That is, starting the economy with more residential capital (or conversely, destroying some residential capital) neither raises nor lowers welfare. Intuitively, giving one unit of residential capital to a household raises her welfare (see Eq. (26) below), but it also lowers residential investment. This in turn reduces aggregate demand and employment, and reduces other households' welfare. In the baseline setting, these demand externalities are so strong that they completely undo the direct value of residential capital.

The externalities are very powerful in part because of the GHH preferences in (2). To provide a more transparent cost-benefit analysis for policy interventions, in this section we work with a slight modification of the model (all of the results also hold in the baseline setting). Suppose at date 0 , and only at this date, households' preferences over consumption and labor are given by the separable form, $u\left(c_{0}\right)-v_{0}\left(l_{0}\right)$, as opposed to the GHH form, $u\left(\hat{c}_{0}-v\left(l_{0}\right)\right)$. With a slight abuse of terminology, we use $c_{0}$ to denote consumption at date 0 as opposed to net consumption, and $y_{0}=F\left(k_{0}, l_{0}\right)$ to denote output at date 0 as opposed to net output. We also abstract away from adjustment costs so that the competitive equilibrium decumulates the excess capital in a single period. Lemma 2 in Appendix A.2 establishes that a sufficiently high level of overbuilding triggers a demand-driven recession also in this setting.

\subsection{Ex-post policies: Slowing down disinvestment}

A natural question in this environment concerns the optimal government policy regarding residential investment. On the one hand, since overbuilding is associated with residential capital, it might sound intuitive that the planner should not interfere with the decumulation of this type of capital. On the other hand, policies that support the housing market have been widely used during and after the Great Recession. We next formally analyze the desirability of these types of policies.

We start by revisiting the representative household's equilibrium trade-off for residential investment, which provides a useful benchmark for the planner's trade-off. Imagine a household who already invested up to the target level of residential capital, 
$h_{1}=h^{*}$, and who is considering to invest an additional unit. Appendix A.2 defines the value function, $W_{0}\left(h_{1}\right)$, for this household and shows that,

$$
\left.\frac{d_{+} W_{0}\left(h_{1}\right)}{d h_{1}}\right|_{h_{1}=h^{*}}=u^{\prime}\left(\bar{c}_{0}\right)\left(\frac{1-\delta^{h}}{1+r_{1}}-1\right)<0 .
$$

Here, $\frac{d_{+} W_{0}\left(h_{1}\right)}{d h_{1}}$ denotes the right derivative, and the inequality follows since $r_{1}=0$. The household assigns a positive value, $1-\delta^{h}$, to the excess unit of residential capital: Even though she does not receive any flow utility in the short run, she will benefit from the nondepreciated part in the future. Nonetheless, she chooses $h_{1}=h^{*}$ in equilibrium because the benefit is lower than the private cost of capital.

Next consider a constrained planner who can fully determine residential investment at date 0 , but cannot interfere with the remaining market allocations either at date 0 or in the future. Appendix A.2 defines the value function, $W_{0, p l}\left(h_{1}\right)$, for this constrained planner and shows that,

$$
\left.\frac{d_{+} W_{0, p l}\left(h_{1}\right)}{d h_{1}}\right|_{h_{1}=h^{*}}=u^{\prime}\left(\bar{c}_{0}\right)\left(\left(1-\delta^{h}\right)-\left(1-\tau_{0}\right)+\frac{d c_{0}}{d h_{1}} \tau_{0}\right) .
$$

Here, $\tau_{0}>0$ is the labor wedge, which captures the severity of the demand shortage (as in the baseline model). Comparing Eqs. (26) and (27) illustrates that the (direct) social benefit of building is the same as the private benefit, $1-\delta^{h}>0$. However, the social cost is lower, $1-\tau_{0}<1$, which leads to the following result.

Proposition 4 (Slowing Down Disinvestment). Consider the equilibrium characterized in Lemma 2. There exists $\tilde{b}_{0}$ such that, if $b_{0}>\tilde{b}_{0}$, then the planner chooses a higher level of residential investment than the target level, $h_{1, p l}>h^{*}$.

The planner recognizes that residential investment increases aggregate demand and employment. This is socially beneficial, and the benefits are captured by the labor wedge, $\tau_{0}$, because employment is below its efficient level. Thus, the demand externalities lower the social cost of building. The low cost, by itself, does not create sufficient rationale for intervention - the planner also considers the benefit. Proposition 4 shows that the planner intervenes as long as the initial overbuilding is sufficiently large. Eqs. (26) and (27) suggest further that this is more likely if the overbuilt capital is more durable, so that $1-\delta^{h}$ is higher 18 Intuitively, durable capital - such

\footnotetext{
${ }^{18}$ We could formalize this observation in a version of the model with multiple types of capital as in the setup of Proposition 2. In that case, the analog of Proposition 4 would imply the planner
} 
as residential capital - has a relatively high value, even if it is overbuilt in the short run, because it helps to economize on future investment.

Eq. (27) illustrates an additional benefit of investing in durable capital, captured by the nonnegative term, $\frac{d c_{0}}{d h_{1}} \tau_{0}$ (see Appendix A.2. Intuitively, bringing the nondepreciated part of the capital to date 1 creates a future wealth effect that raises consumption not only at date 1 , but also at date 0 , which further increases employment. This channel is reminiscent of the forward guidance policies that create a similar wealth effect by committing to low interest rates in the future 19

Our model, thus, provides a rationale for policies that support residential investment during an investment overhang. In practice, the planner can do this by increasing housing demand, e.g., with mortgage subsidies or modifications, or by increasing housing supply, e.g., with construction subsidies. Both types of policies can internalize the inefficiency in our model. Note, however, that the demand side policies tend to increase house prices, whereas the supply side policies tend to decrease them. The demand side interventions might be more appropriate if one considers additional ingredients, such as financial frictions, that are left out of our analysis.

To isolate the trade-offs, we have focused on a planner who can only influence residential investment. In practice, the policymakers can use various other tools to fight a liquidity trap. Eq. 27 would also apply in variants of the model in which the planner optimally utilizes multiple policies. In those variants, the equation would imply that the planner should stimulate residential investment as long as she cannot substantially mitigate the liquidity trap (i.e., lower the labor wedge, $\tau_{0}$ ) by using only the other feasible policies. This prediction is arguably applicable to various developed economies in recent years, e.g., the US and Europe, that have featured zero nominal interest rates with low employment and output.

\subsection{Ex-ante policies: Restricting investment}

We next analyze whether the planner can improve welfare via ex-ante interventions. To this end, consider the baseline model with an ex-ante period, date -1 . Suppose also that the economy can be in one of two states at date 0 , denoted by $s \in\{H, L\}$. State $L$ is a low-demand state in which the target level of housing capital is $h^{*}$ as

intervenes less often (greater $\tilde{b}_{0}$ ) for less durable types of capital (smaller $1-\delta^{h}$ ). In fact, the planner would not intervene $\left(\tilde{b}_{0}=\infty\right)$ if the capital was completely nondurable $\left(1-\delta^{h}=0\right)$.

${ }^{19}$ In fact, increasing $h_{1}$ also lowers the future interest rate, $r_{2}$, in our setting. Note, however, that future output remains efficient in our model, $y_{1}=s\left(k_{1}\right)$, whereas it exceeds the efficient level in environments with forward guidance (Werning, 2012). 
before (and the planner has no tools for ex-post intervention). State $H$ is a highdemand state in which the utility function in (2) is modified so that the target level of housing capital is $\left(1+\lambda^{H}\right) h^{*}$ for some $\lambda^{H}>0$. Let $\pi^{H} \in(0,1)$ denote the ex-ante probability of the high-demand state at date 0 . The economy starts with $h_{-1}=\left(1+\lambda^{H}\right) h^{*}$ and $k_{-1}=k^{*}$.

The model captures a situation in which the housing demand has recently increased relative to its historical level, and the economy has already adjusted to this new level. However, there is a possibility that the current state is not sustainable and the housing demand will revert back to its historical average ${ }^{20}$ We also envision that $\pi^{H}$ is large, so that the representative household believes the high-demand state is likely to persist, but also that $\pi^{H}<1$ so that there is room for precautionary policies.

We first characterize the choice of $h_{0}$ and $k_{0}$ in the competitive equilibrium, which we then compare with the constrained efficient allocations. The preferences in (2) imply that the opportunity cost of consuming housing services below target is very large. Consequently, households invest in residential capital according to their demand in state $H$, that is, $h_{0}=\left(1+\lambda^{H}\right) h^{*}$. Thus, the degree of overbuilding in state $L$ is now endogenized, $b_{0}=\lambda^{H}{ }^{21}$ Nonresidential investment, $k_{0}$, is in turn determined by a standard optimality condition,

$$
u^{\prime}\left(c_{-1}\right)=\beta\left(\pi^{H}\left(R_{0}^{H}+1-\delta^{k}\right) u^{\prime}\left(c_{0}^{H}\right)+\left(1-\pi^{H}\right)\left(R_{0}^{L}+1-\delta^{k}\right) u^{\prime}\left(c_{0}^{L}\right)\right) .
$$

The appendix completes the characterization, and establishes that there is an anticipated liquidity trap in state $L$ of date 0 if $\lambda^{H}$ and $\pi^{H}$ are sufficiently high.

Next consider a constrained planner that can determine households' date -1 allocations, including the choice of $h_{0}, k_{0}$, but cannot interfere with equilibrium allocations starting date 0 . Like households, the planner also optimally chooses $h_{0, p l}=\left(1+\lambda^{H}\right) h^{*}$. However, the planner's choice of nonresidential capital, $k_{0, p l}$, is potentially different. The appendix describes the constrained planning problem and characterizes the planner's optimality condition as,

$u^{\prime}\left(c_{-1}\right)=\beta\left(\pi^{H}\left(R_{0}^{H}+1-\delta^{k}\right) u^{\prime}\left(c_{0}^{H}\right)+\left(1-\pi^{H}\right)\left(R_{0}^{L}+\left(1-\tau_{0}\right)\left(1-\delta^{k}\right)\right) u^{\prime}\left(c_{0}^{L}\right)\right)$.

Conditions (28) and (29) are similar except that the planner penalizes the nondepre-

\footnotetext{
${ }^{20}$ An alternative interpretation is to think of state $H$ as capturing the historical housing demand. In this case, state $L$ represents a "new normal" in which housing demand permanently declines.

${ }^{21}$ The feature that overbuilding is determined exactly by the demand in state $H$ is extreme. However, a similar outcome would also obtain in less extreme versions as long as $\pi^{H}$ is sufficiently large.
} 
ciated part of the capital in state $L$, since $1-\tau_{0}<1$, which leads to the following.

Proposition 5 (Restricting Ex-ante Investment). Consider the setup with an ex-ante period, described in Lemma 3 in Appendix A.2. The constrained planner chooses a lower level of investment compared to the competitive equilibrium, $k_{0, p l}<k_{0}$.

Intuitively, some of the capital invested at date -1 remains nondepreciated at date 0 , which in turn lowers aggregate demand and exacerbates the recession in state $L$. Private agents do not internalize these negative externalities and overinvest in capital from a social point of view. In our stylized model, the inefficiency does not show up in residential capital, because the extreme preferences in (2) imply a corner solution. In alternative formulations with somewhat elastic housing demand, the planner would optimally restrict ex-ante investment in both types of capital. In fact, Eq. 29] suggests that the externality is particularly strong for more durable types of capital, because the inefficiency is driven by the nondepreciated part.

Proposition 5 is reminiscent of the results in a recent literature, e.g., Korinek and Simsek (2014) and Farhi and Werning (2013), which investigate the implications of aggregate demand externalities for ex-ante macroprudential policies in financial markets. For instance, Korinek and Simsek (2014) show that, in the run-up to liquidity traps, private agents take on too much debt, because they do not internalize that leverage reduces aggregate demand. We complement this analysis by showing that aggregate demand externalities also create inefficiencies for ex-ante physical investment. Our model highlights a distinct mechanism, and generates policy implications that are not the same as the macroprudential policies typically emphasized in this literature. We provide a rationale for restricting ex-ante investment regardless of whether investment is financed by debt or other means.

In practice, the planner could restrict investment by using a variety of direct policies, e.g., taxes, quantity restrictions, or financing restrictions. A natural question is whether the planner should also use the monetary policy. The US Fed has been criticized for keeping the interest rate low in the run-up to the Great Recession. Our next result investigates whether a contractionary policy that raises the interest rate at date -1 above its natural level might be desirable.

Proposition 6 (Jointly Optimal Monetary and Investment Policy). Consider the setup in Proposition 5. Suppose the planner chooses the interest rate, $r_{0}$, at date -1, in addition to controlling the houeshold's ex-ante allocations. It is optimal for this planner to set $r_{0}=r_{0}^{*}$ and implement $y_{-1}=s\left(k_{-1}\right)$. 
Put differently, once the investment (restricting) policies are in place, it is optimal for the monetary policy to pursue its myopic output stabilization goal described in (11). The constrained efficient outcome (characterized by condition (29)) is to reduce the investment at date -1 while increasing consumption, so that there is some reallocation but not a recession at date -1 . The investment policies implement this outcome by allowing the interest rate to be determined in equilibrium so as to clear the goods market (the liquidity trap does not bind at date -1 under our assumptions). In contrast, setting a high level of the interest rate, $r_{0}>r_{0}^{*}$, reduces investment while also creating an inefficient recession at date -1.22

Let us summarize the insights from our welfare analyses in this section. Expost, once the economy is in the liquidity trap, welfare can be improved by policies that stimulate investment, including investment in the overbuilt capital. Ex-ante, before the economy enters the liquidity trap, welfare can be improved by policies that restrict investment. The optimal ex-post and ex-ante policies share the broad principle that they intertemporally substitute investment from periods that feature efficient outcomes to periods (or states) that feature deficient demand. Intertemporal substitution is less costly for more durable types of capital that deliver a utility flow over a long horizon of time. Hence, our analysis also suggests that the policy interventions are particularly desirable for more durable types of capital.

\section{Conclusion}

We have presented a model of investment hangover in the Great Recession that combines both Austrian and Keynesian features. On the Austrian side, the recession is precipitated by overbuilding in the residential sector, which necessitates a reallocation of resources to other sectors. The required reallocation is exacerbated by the durability of residential capital, which prevents depreciation from naturally erasing the overbuilt capital. On the Keynesian side, a lower bound on interest rates slows down reallocation and creates an aggregate demand shortage. The demand shortage can also reduce investment in sectors that are not overbuilt, leading to a severe recession. Eventually, nonresidential investment recovers, but the slump in the residential sector continues for a long time.

\footnotetext{
${ }^{22}$ That said, if the planner does not have access to the investment policies described above, or faces additional costs in implementing these policies, then she might want to resort to constrained monetary policy as a second-best measure.
} 
The model yields predictions that are consistent with the broad trends of GDP, residential investment, and investment in the Great Recession. In particular, the model explains why housing investment collapsed and has not really recovered, and why other types of investment also declined initially, but then recovered much more robustly. We need both Keynesian and Austrian features to obtain these empirically accurate predictions.

The model also features aggregate demand externalities, with several policy implications for investment. Welfare can be improved by ex-post policies that slow down the decumulation of residential capital, as well as ex-ante policies that restrict the accumulation of capital. These policies intertemporally substitute investment towards periods that feature deficient demand. It is preferable to restrict ex-ante investment directly, instead of using contractionary monetary policy.

Although we have focused on the Great Recession, the model is more widely applicable. Perhaps the most straightforward extension is to overbuilding in sectors other than housing. In the 1930s, when both Hayek and Keynes wrote, speculative overbuilding was seen as a critical impetus to recessions, but the focus was more on railroads and perhaps industrial plant than on housing. In our model, such extensions would require only a relabeling of variables.

Less obvious is the extension to other forms of restrictions on interest rates, such as currency unions, which also slow down the Austrian reallocation of resources from the overbuilt sector to others. In the recent European context, such restrictions may have played a critical role, and generated Keynesian aggregate demand effects along the lines suggested by our model. We leave an elaboration of these mechanisms to future work.

\section{References}

Abraham, Katharine G., and Lawrence F. Katz (1986), "Cyclical Unemployment: Sectoral Shifts or Aggregate Disturbances?" Journal of Political Economy, 94(3), p.367-388.

Adam, Klaus, and Roberto M. Billi (2006), "Optimal Monetary Policy under Commitment with a Zero Bound on Nominal Interest Rates," Journal of Money, Credit \& Banking, 38(7), p.1877-1905.

Auerbach, Alan J., and Maurice Obstfeld (2005), "The Case for Open-Market Purchases in a Liquidity Trap," American Economic Review, p.110-137. 
Beaudry, Paul, and Franck Portier (2004), "An Exploration into Pigou's Theory of Cycles," Journal of Monetary Economics, 51, p.1183-1216.

Beaudry, Paul, and Franck Portier (2013), "News Driven Business Cycles: Insights and Challenges," NBER Working Paper no. 19411.

Beaudry, Paul, Dana Galizia, and Franck Portier (2014), "Reconciling Hayek's and Keynes Views of Recessions," NBER Working Paper no. 20101.

Blanchard, Olivier, and Peter Diamond (1989), "The Beveridge Curve," Brookings Papers on Economic Activity, 1989(1), p.1-60.

Boldrin, Michele, Carlos Garriga, Adrian Peralta-Alva, and Juan M. Sánchez (2013), "Reconstructing the Great Recession," FRB of St. Louis Working Paper.

Brunnermeier, Markus (2009), "Deciphering the Liquidity and Credit Crunch of 200708," Journal of Economic Perspectives, 23, p.77-100.

Caballero, Ricardo J. (1999), "Aggregate Investment," in Taylor, J. B. and M. Woodford, eds., Handbook of Macroeconomics, Amsterdam: North Holland.

Caballero, Ricardo J., Eduardo M. Engel, and John C. Haltiwanger (1995) "PlantLevel Adjustment and Aggregate Investment Dynamics," Brookings Papers Economic Activity, 1995(2), p.1-39.

Caballero, Ricardo, and Emmanuel Farhi (2014), "The Safety Trap," NBER Working Paper no. 19927.

Caballero, Ricardo, and Mohamad Hammour (1996), "On the Ills of Adjustment," Journal of Development Economics, 51(1), p.161 192.

Campbell, Jeffrey R. and Zvi Hercowitz (2005), "The Role of Collateralized Household Debt in Macroeconomic Stabilization," NBER working paper no. 11330.

Campello, Murillo, John Graham, and Campbell Harvey (2010), "The Real Effects of Financial Constraints: Evidence from a Financial Crisis," Journal of Financial Economics, 97, p.470-487.

Christiano, Larry, Eichenbaum, Martin and Sergio Rebelo (2011), "When is the Government Spending Multiplier Large?" Journal of Political Economy, 19, pp. 78-121.

Christiano, Lawrence, Martin Eichenbaum, and Mathias Trabandt (2014), "Understanding the Great Recession," NBER Working Paper no. 20040.

Chodorow-Reich, Gabriel (2014), "The Employment Effects of Credit Market Disruptions: Firm-level Evidence from the 2008-09 Financial Crisis," Quarterly Journal of Economics, 129, p.1-59. 
Clark, J. Maurice (1917), "Business Acceleration and the Law of Demand: a Technical Factor in Economic Cycles," Journal of Political Economy, 25, p.217-235.

Correia, Isabel, Emmanuel Farhi, Juan Pablo Nicolini and Pedro Teles (2013), "Unconventional Fiscal Policy at the Zero Bound," American Economic Review, 103(4), p.1172-1211.

Davila, Eduardo (2015), "Dissecting Fire Sale Externalities," NYU Working Paper. Davis, Morris A. and Jonathan Heathcote (2005), "Housing and the Business Cycle," International Economic Review, 46, p.751-784.

Davis, Steven J. and John Haltiwanger (1990), "Gross job creation and destruction: microeconolnic evidence and macroeconomic implications," NBER Macroeconomics Annual, 5, p.123-168.

DeLong, Bradford (1990), “'Liquidation' Cycles: Old-Fashioned Real Business Cycle Theory and the Great Depression," NBER Working paper no. 3546.

Desai, Mihir A. and Austan Goolsbee (2004), "Investment, Overhang, and Tax Policy," Brookings Papers on Economic Activity, 2004.2, p.285-355.

Eckaus, Rirchard S. (1953), "The Acceleration Principle Reconsidered," Quarterly Journal of Economics, 67, p.209-230.

Eggertsson, Gauti, and Paul Krugman (2012), "Debt, Deleveraging, and the Liquidity Trap," Quarterly Journal of Economics, 127(3), p.1469-1513.

Eggertsson, Gauti, and Neil Mehrotra (2014), "A Model of Secular Stagnation," NBER Working Paper no. 20574.

Eggertsson, Gauti, and Michael Woodford (2003), "The Zero Bound on Interest Rates and Optimal Monetary Policy", Brookings Papers on Economic Activity, 2003(1), p.139-233.

Farhi, Emmanuel and Iván Werning (2013), "A Theory of Macroprudential Policies in the Presence of Nominal Rigidities", NBER Working Paper no. 19313.

Fisher, Jonas D.M. (2007), "Why Does Household Investment Lead Business Investment Over the Business Cycle? Journal of Political Economy, 115, p.141-168.

Gertler, Mark, and Peter Karadi (2011), "A Model of Unconventional Monetary Policy," Journal of Monetary Economics, 58, p.17-34.

Gertler, Mark, and Nobuhiro Kiyotaki (2011), "Financial Intermediation and Credit Policy in Business Cycle," in Handbook of Monetary Economics, North Holland: Elsevier. 
Gervais, Martin (2002), "Housing Taxation and Capital Accumulation," Journal of Monetary Economics, 49.7, p.1461-1489.

Greenwood, Jeremy and Zvi Hercowitz (1991), "The Allocation of Capital and Time Over the Business Cycle," Journal of Political Economy, 99, p.1188-1214.

Greenwood, Jeremy, Zvi Hercowitz, and Gregory W. Huffman (1988), "Investment, Capacity Utilisation and the Real business Cycle," American Economic Review, 78, p. $402-417$.

Guerrieri, Veronica and Guido Lorenzoni (2011), "Credit Crises, Precautionary Savings, and the Liquidity Trap," NBER Working Paper no. 17583.

Hall, Robert E. (2011), "The Long Slump," American Economic Review 101(2), p.431-469.

Hart, Oliver, and Luigi Zingales (2011), "Inefficient Provision of Liquidity," NBER Working Paper no. 17299.

Hayek, Friedrich (1931), Prices and Production, London: Routledge \& Kegan Paul. He, Zhiguo, and Péter Kondor (2014), "Inefficient Investment Waves," NBER Working Paper no. 18217.

He, Zhiguo, and Arvind Krishnamurthy (2014), "A Macroeconomic Framework for Quantifying Systemic Risk," NBER Working Paper no. 19885.

House, Christopher L. (2014), "Fixed Costs and Long-lived Investments," Journal of Monetary Economics, 68, p.86-100.

Iacoviello, Matteo (2005), "House Prices, Borrowing Constraints, and Monetary Policy in the Business Cycle," American Economic Review, 95, p.739-764.

Iacoviello, Matteo, and Marina Pavan (2013), "Housing and Debt Over the Life Cycle and Over the Business Cycle," Journal of Monetary Economics, 60, p.221-238.

Jaimovich, Nir and Sergio Rebelo (2009), "Can News about the Future Drive the Business Cycle?" American Economic Review, 99, p.1097-1118.

Jappelli, Tullio, and Luigi Pistafferi (2010), "The Consumption Response to Income Changes," Annual Review of Economics, 2, p.479-506.

Jeanne, Olivier, and Lars E. O. Svensson (2007), "Credible Commitment to Optimal Escape From a Liquidity Trap: The Role of the Balance Sheet of an Independent Central Bank," American Economic Review, p.474-490. 
Jermann, Urban, and Vincenzo Quadrini (2012), "Macroeconomic Effects of Financial Shocks," American Economic Review, 102(1), p.238-71.

Kaplan, Greg, and Giovanni L. Violante (2014), "A Model of the Consumption Response to Fiscal Stimulus Payments," Econometrica, 82, p.1199-1239.

Kiyotaki, Nobuhiro, Alexander Michaelides, and Kalin Nikolov (2011), "Winners and Losers in Housing Markets," Journal of Money, Credit and Banking, 43, p.255-296.

Korinek, Anton and Alp Simsek (2014), "Liquidity Trap and Excessive Leverage," NBER Working Paper no. 19970.

Krugman, Paul (1998), "The Hangover Theory," Slate Magazine, available at: http://www.slate.com/id/9593. (Accessed: Jul 5, 2014).

Krugman, Paul (1998), "It's Baaack: Japan's Slump and the Return of the Liquidity Trap," Brookings Papers on Economic Activity, p.137-205.

Leamer, Edward E. (2007), "Housing is the Business Cycle," NBER Working Paper no. 13428 .

Lilien, David M. (1982), "Sectoral Shifts and Cyclical Unemployment," The Journal of Political Economy, p.777-793.

Lorenzoni, Guido (2008), "Inefficient Credit Booms," Review of Economic Studies, 75(3), p.809-833.

Metzler, Lloyd (1941), "The Nature and Stability of Inventory Cycles," Review of Economics and Statistics, 23, p.113-129.

Mian, Atif and Amir Sufi (2014), The House of Debt, Chicago: University of Chicago Press.

Mian, Atif and Amir Sufi (2015), "What Explains the 2007-2009 Drop in Employment?", Econometrica, forthcoming.

Mian, Atif, Kamelesh Rao, and Amir Sufi (2013), "Household Balance Sheets, Consumption, and the Economic Slump," Quarterly Journal of Economics, 128(4), p.1687-1726.

Piazzesi, Monika, Martin Schneider, and Selale Tuzel (2007), "Housing, Consumption and Asset Pricing," Journal of Financial Economics, 83(3), p.531-569.

Samuelson, Paul (1939), "Interactions Between the Multiplier Analysis and the Principle of Acceleration," Review of Economic Statistics, 21(2), p.75-78 
Schmitt-Grohé, Stephanie, and Martín Uribe (2012), "The Making of a Great Contraction with a Liquidity Trap and a Jobless Recovery," NBER Working Paper no. 18544.

Summers, Lawrence (2013), "Why Stagnation Might Prove to be the New Normal," The Financial Times.

Stein, Jeremy C. (2012), "Monetary Policy as Financial Stability Regulation," Quarterly Journal of Economics, 127, p.57-95.

Thomas, Julia K. (2002), "Is Lumpy Investment Relevant for the Business Cycle?" Journal of Political Economy, 110, p.508-534.

Werning, Iván (2012), "Managing a Liquidity Trap: Monetary and Fiscal Policy", NBER Working Paper no. 17344. 


\section{A Online Appendix: Omitted extensions}

This appendix completes the analysis of the extensions of the baseline model discussed in the main text. The online appendix $\mathrm{B}$ contains the proofs of omitted results in the main text as well as this appendix.

\section{A.1 Consumption response and the Keynesian multiplier}

The baseline model features a representative household whose consumption satisfies the Euler equation. However, the Euler equation cannot fully capture the behavior of consumption in response to income changes in the data (see Jappelli and Pistaferri, 2010). We next modify the model by introducing constrained agents that have high MPCs out of income. We show that, unlike the baseline model, this version of the model can account for the drop in consumption earlier in the recession. The model also features a Keynesian income multiplier, which exacerbates the recession and reinforces the investment accelerator mechanism.

Suppose, in addition to the representative household analyzed earlier, there is an additional mass $l^{\text {tr }}$ of households which we refer to as income-trackers. These agents are excluded from financial markets so that they consume all of their income, that is, their MPC is equal to 1 (for simplicity). Each income-tracker inelastically supplies 1 unit of labor in a competitive market for a wage level $w_{t}^{t r}$, which provides her only source of income. Consequently, total consumption is now given by $c_{t}+w_{t}^{t r} l^{t r}$, where $c_{t}$ is the consumption of the representative household and $w_{t}^{t r} l^{t r}$ denotes the consumption of income-trackers.

The aggregate production function can generally be written as $\tilde{F}\left(k_{t}, l_{t}, l^{t r}\right)$, where $l_{t}$ is the labor supply by the representative household and $l^{t r}$ is the total labor supply by income-trackers. To simplify the analysis, we focus on the special case $\tilde{F}\left(k_{t}, l_{t}, l^{t r}\right)=F\left(k_{t}, l_{t}\right)+\eta^{t r} l^{t r}$, where $F$ is a neoclassical production function and $\eta^{t r}>0$ is a scalar. We continue to use the notation $y_{t}=F\left(k_{t}, l_{t}\right)-v\left(l_{t}\right)$ to refer to net output excluding the supply of income-trackers. Total net output is given by $y_{t}+\eta^{t r} l^{t r}$. The rest of the model is the same as in the previous section.

In view of these assumptions, the economy is subject to the resource constraint,

$$
c_{t}+i_{t}^{k}+i_{t}^{h}+w_{t}^{t r} l^{t r}=y_{t}+\eta^{t r} l^{t r} \leq s\left(k_{t}\right)+\eta^{t r} l^{t r} .
$$


Lemma 4 in Appendix B characterizes the income-trackers' wage level as

$$
w_{t}^{t r}=\psi\left(k_{t}, y_{t}\right) \eta^{t r}
$$

Here, $\psi\left(k_{t}, y_{t}\right) \in[0,1]$ is a measure of efficient resource utilization (more specifically, $\psi=1-\tau$ where $\tau$ is the labor wedge). It is an increasing function of $y_{t}$ and satisfies $\psi=1$ when the output is at its efficient level, $y_{t}=s\left(k_{t}\right)$. Intuitively, the demand shortage lowers factor returns, including the wages of income trackers.

Combining Eqs. A.1 and A.2 implies

$$
y_{t}=c_{t}+k_{t+1}-(1-\delta) k_{t}+i_{t}^{h}+\left(\psi\left(k_{t}, y_{t}\right)-1\right) \eta^{t r} l^{t r},
$$

for each $t \in\{0,1, . ., T-1\}$. This expression illustrates a Keynesian cross as well as a Keynesian income multiplier in our setting. The equilibrium obtains when the actual and demanded net outputs are equal, as in a typical the Keynesian cross. Moreover, total demand depends on the output $y_{t}$ through income-trackers' consumption, illustrating the multiplier. Consider, for instance, a shock to aggregate demand that lowers net output. This lowers income-trackers' income and their consumption, which in turn induces a second round reduction in aggregate demand and output, and so on.

Next consider a residential investment shock that lasts $T$ periods as in the previous section. We conjecture an equilibrium with a liquidity trap at all dates $t \in\{0,1, . ., T-1\}$. As before, the break-even condition 23 holds. Eqs. A.3 and (23) can then be solved backwards starting with $k_{T}=\bar{k}$. The next result establishes the existence of an equilibrium, and characterizes the behavior of consumption in equilibrium.

Proposition 7 (Consumption Response). Consider the model with mass $l^{\text {tr }}$ of income-trackers and the adjustment length $T \geq 1$. Suppose Assumptions 1-2 and Assumption $3^{\text {tr }}$ in Appendix B hold.

(i) There exists $i^{h, 1}$ such that if $i^{h}<i^{h, 1}$, then there is an equilibrium path $\left\{k_{t}, y_{t-1}\right\}_{t=1}^{T}$, which solves Eqs. 23) and A.3 along with $k_{T}=\bar{k}$. Any equilibrium features a liquidity trap at each date $t \in\{0, . ., T-1\}$ with $r_{t+1}=0$ and $y_{t}<s\left(k_{t}\right)$.

(ii) There exists $l_{1}^{\text {tr }}$ such that if $l^{\text {tr }}>l_{1}^{\text {tr }}$, then total consumption at date 0 (in any equilibrium) is below its steady-state level, that is

$$
c_{0}+w_{0}^{t r} l^{t r}<c^{*}+\eta^{t r} l^{t r} .
$$



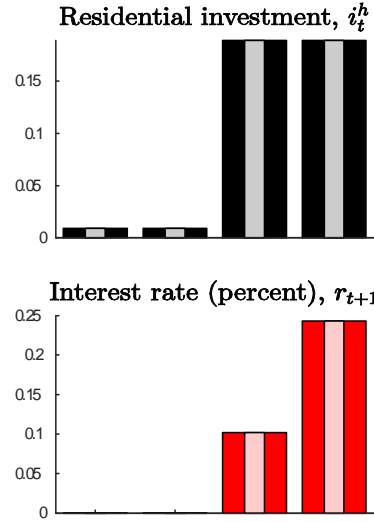

Net consumption, $c_{t}$

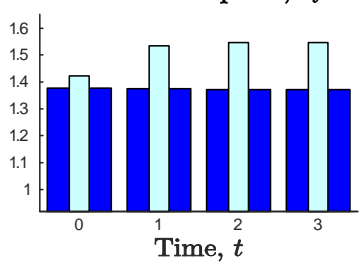

Nones capital, $k_{t}$

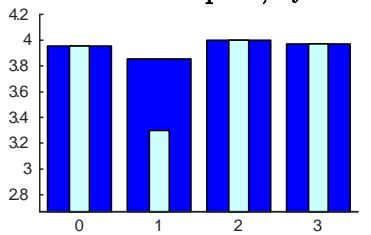

Net output, $y_{t}$

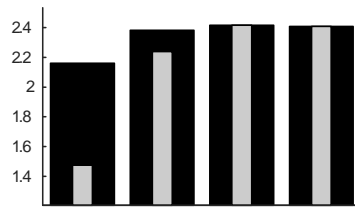

Labor, $l_{t}$

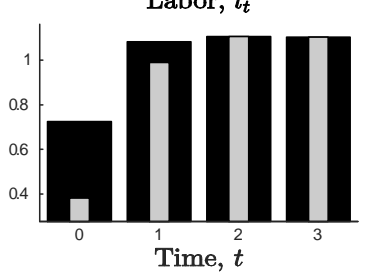

Nonres investment, $i_{t}^{k}$

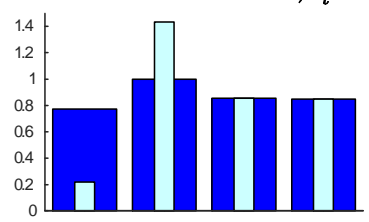

Actual output

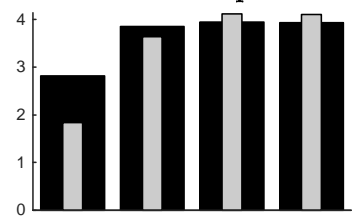

Labor wedge, $\tau_{t}$

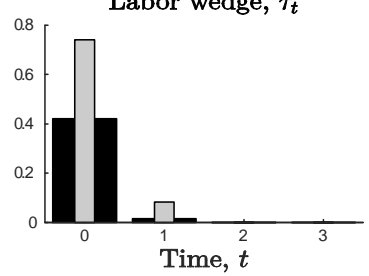

Figure 7: The dynamic equilibrium with income-trackers (light bars) compared to the equilibrium without income-trackers (dark bars).

The main result of this section is the second part, which establishes conditions under which overbuilding also lowers total consumption at date 0 in any equilibrium ${ }^{23}$ When the economy is in a liquidity trap, output falls due to the demand shortage, which lowers income-trackers' consumption. With sufficiently many income-trackers, this also reduces total consumption in contrast to the baseline model. The light bars in Figure 7 illustrate this result by plotting the dynamic equilibrium using the same parameters as before except for the new parameters $\eta^{t r}, l^{t r}>0$. Consumption declines early in the recession, and it recovers later in the recession due to the recovery in output. Hence, this version of the model can generate a nonmonotonic response in consumption, similar to the nonmonotonic response of investment identified in Proposition 3 .

It follows that this version of the model can explain the asymmetric recovery from the Great Recession depicted in Figure 1. In the first phase of the recession, consumption as well as nonresidential investment simultaneously fall, triggering a deep recession. In the second phase, the boom in nonresidential investment increases

\footnotetext{
${ }^{23}$ The equilibrium is unique in all of our numerical simulations. However, there could in principle be multiple equilibria because Eq. A.3 represents an intersection of two increasing curves in $Y_{t}$.
} 
output, which also increases consumption. Hence, the second phase is a partial and asymmetric recovery in which the residential sector is left behind, as in the aftermath of the Great Recession.

Figure 7 also contrasts this equilibrium with the earlier equilibrium without income-trackers, which is plotted with dark bars. Note that the equilibrium in this section features a greater drop in output and employment, as well as a greater labor wedge. Intuitively, the Keynesian income multiplier aggravates the recession. Perhaps less obviously, the equilibrium also features a more severe drop in investment at date 0 , followed by a stronger recovery at date 1 . Intuitively, a more severe recession implies a lower return to capital, which in turn lowers investment at date 0 . Put differently, the Keynesian income multiplier exacerbates the investment accelerator mechanism. The decline in investment at date 0 further lowers net output and consumption, aggravating the Keynesian income multiplier. In this sense, the multiplier and the accelerator mechanisms reinforce each other.

\section{A.2 Policy analysis with separable preferences}

We next complete the analysis of the model with separable preferences described and used in Section 5. We first establish the analog of Proposition 1 for this setting. To this end, let $\bar{c}_{0}$ and $\bar{k}$ respectively denote the maximum level of consumption and investment characterized in Section 3. The aggregate demand is then bounded from above, $y_{0} \leq \bar{y}_{0}$, where

$$
\bar{y}_{0}=\bar{y}_{0} \equiv \bar{k}-\left(1-\delta^{k}\right) k_{0}+\bar{c}_{0}+\left(\delta^{h}-b_{0}\left(1-\delta^{h}\right)\right) h^{*}
$$

as in Eq. 19 in the main text.

Next consider the efficient level of employment at date 0 . The efficiency implies the household's intratemporal condition holds, $w_{0} u^{\prime}\left(c_{0}\right)=v^{\prime}\left(l_{0}\right)$, and the equilibrium wage level is determined by the labor's marginal product, $w_{0}=F_{l}\left(k_{0}, l_{0}\right)$. Combining these conditions is equivalent to setting the labor wedge to zero, where the labor wedge is now given by,

$$
\tau_{0}=1-\frac{v_{0}^{\prime}\left(l_{0}\right)}{u^{\prime}\left(c_{0}\right) F_{l}\left(k_{0}, l_{0}\right)} .
$$

Let $l_{0}^{*, s e p}$ denote the efficient level of output at date 0 (when there is a liquidity trap) characterized by setting $\tau_{0}=0$ when $c_{0}=\bar{c}_{0}$. This also implies an efficient level of output, $y_{0}^{*, s e p}=F\left(k_{0}, l_{0}^{*, s e p}\right)$.

As in Section 3, the equilibrium depends on a comparison of the maximum level 
of demand, $\bar{y}_{0}$, with the efficient supply, $y_{0}^{*, s e p}$. Let $\bar{b}_{0}^{\text {sep }}$ denote the threshold level of overbuilding that ensures $\bar{y}_{0}=y_{0}^{*, s e p}$, that is,

$$
\bar{b}_{0}^{\text {sep }}=\frac{\bar{k}-\left(1-\delta^{k}\right) k_{0}+\bar{c}_{0}+\delta^{h} h^{*}-y_{0}^{*, s e p}}{\left(1-\delta^{h}\right) h^{*}} .
$$

We then have the following analogue of Proposition 1 .

Lemma 2. Consider the modified model with separable preferences at date 0 . The competitive equilibrium decumulates the excess residential capital in a single period, $h_{1}=h^{*}$. If the overbuilding is sufficiently large, $b_{0}>\bar{b}_{0}^{\text {sep }}\left(k_{0}\right)$, then the date 0 equilibrium features a liquidity trap with,

$$
r_{1}=0, \quad \tau_{0}>0, \quad y_{0}=\bar{y}_{0}<F\left(k_{0}, l_{0}^{*, s e p}\right), \text { and } l_{0}<l_{0}^{*, s e p}
$$

\section{A.2.1 Ex-post welfare analysis}

Next suppose the overbuilding is sufficiently large so that the economy is in a recession. We next respectively define the household's and the planner's value functions and derive their optimality conditions. Note that choosing $h_{1}<h^{*}$ is sub-optimal in view of the preferences (2). We thus consider the value functions over the region $h_{1} \geq h^{*}$.

The household's problem can then be written as (cf. problem (5)),

$$
\begin{aligned}
W_{0}\left(h_{1}\right)= & \max _{\left\{c_{t}, a_{t+1}\right\}_{t}} \sum_{t=0}^{\infty} \beta^{t} u\left(c_{t}\right) \\
\text { s.t. } & c_{t}+a_{t+1}+h_{t+1}=e_{t}+a_{t}\left(1+r_{t}\right)+\Pi_{t}+\left(1-\delta^{h}\right) h_{t} \\
\text { given } h_{0} \geq & h^{*}, h_{1} \geq h^{*} \text { and } h_{t}=h^{*} \text { for each } t \geq 2 .
\end{aligned}
$$

Using the envelope theorem, we obtain,

$$
\left.\frac{d W_{0}\left(h_{1}\right)}{d h_{1}}\right|_{h_{1}=h^{*}}=\beta u^{\prime}\left(c_{1}\right)\left(1-\delta^{h}\right)-u^{\prime}\left(c_{0}\right) .
$$

Combining this with the Euler equation, $u^{\prime}\left(c_{0}\right)=\beta\left(1+r_{1}\right) u^{\prime}\left(c_{1}\right)$, establishes Eq. (26).

Next consider a constrained planner who can (only) control residential investment at date 0 . When $h_{1}$ is in a neighborhood of $h^{*}$, the constrained planning problem can 
be written as,

$$
\begin{aligned}
& W_{0, p l}\left(h_{1}\right)=\max _{c_{0}, k_{1}, y_{0}, l_{0}} u\left(c_{0}\right)-v_{0}\left(l_{0}\right)+\beta V\left(k_{1}, h_{1}\right) \\
& \text { s.t. } k_{1}=\bar{k} \text { and } u^{\prime}\left(c_{0}\right)=\beta u^{\prime}\left(C\left(h_{1}\right)\right) \\
& \text { and } y_{0}=F\left(k_{0}, l_{0}\right)=k_{1}-\left(1-\delta^{k}\right) k_{0}+c_{0}+h_{1}-\left(1-\delta^{h}\right)\left(1+b_{0}\right) h^{*} .
\end{aligned}
$$

Here, $V\left(k_{1}, h_{1}\right)$ denotes the efficient value function characterized as the solution to problem (9), and $C\left(h_{1}\right)$ denotes the efficient level of consumption. The second line captures the liquidity trap constraint that consumption and nonresidential investment are determined by the zero interest rate. The third line captures that output and employment are determined by the aggregate demand at date 0 . Importantly, the output is increasing in $h_{1}$ because a greater level of residential investment increases aggregate demand.

To derive the optimality condition for problem $A .7$, note that the capital stocks $k_{0}$ and $k_{1}=\bar{k}$ are constant, and that the remaining variables, $c_{0}\left(h_{1}\right), y_{0}\left(h_{1}\right), l_{0}\left(h_{1}\right)$, are determined as implicit functions of $h_{1}$. Implicitly differentiating the aggregate demand constraint $A .8$ with respect to $h_{1}$, we obtain,

$$
\frac{d l_{0}}{d h_{1}}=\frac{1+\frac{d c_{0}}{d h_{1}}}{F_{l}\left(k_{0}, l_{0}\right)}=\left(1+\frac{d c_{0}}{d h_{1}}\right) \frac{\left(1-\tau_{0}\right) u^{\prime}\left(c_{0}\right)}{v^{\prime}\left(l_{0}\right)} .
$$

Here, the second equality substitutes the labor wedge from Eq. A.5. Using problem (9) along with the envelope theorem, we also obtain,

$$
\frac{d V_{1}\left(k_{1}, h_{1}\right)}{d h_{1}}=\left(1-\delta^{h}\right) u^{\prime}\left(c_{1}\right)=\left(1-\delta^{h}\right) \frac{u^{\prime}\left(c_{0}\right)}{\beta} .
$$

Here, the second equality uses the Euler equation. Differentiating the objective function of problem (A.7) with respect to $h_{1}$, and using these expressions, we obtain,

$$
\begin{aligned}
\frac{d W_{0, p l}\left(h_{1}\right)}{d h_{1}} & =u^{\prime}\left(c_{0}\right) \frac{d c_{0}}{d h_{1}}-v_{0}^{\prime}\left(l_{0}\right) \frac{d l_{0}}{d h_{1}}+\beta \frac{d V_{1}\left(k_{1}, h_{1}\right)}{d h_{1}}, \\
& =u^{\prime}\left(c_{0}\right)\left(\frac{d c_{0}}{d h_{1}}-\left(1+\frac{d c_{0}}{d h_{1}}\right)\left(1-\tau_{0}\right)+1-\delta^{h}\right) .
\end{aligned}
$$

Rearranging terms establishes Eq. (27). Using this expression, Appendix B proves Proposition 4 and completes the welfare analysis in Section 5.1 . 


\section{A.2.2 Ex-ante welfare analysis}

Next consider the ex-ante welfare analysis in Section 5.2. Recall that the representative household optimally chooses $h_{0}=h^{*}\left(1+\lambda^{H}\right)$, along with $k_{0}$ characterized as the solution to (28). The representative household recognizes that the rental rate of capital in state $L, R_{0}^{L}$, is below its efficient level (due to the demand shortage). This might induce her to choose a lower level of $k_{0}$ as a precaution. A sufficiently low level of $k_{0}$ can, in turn, raise the aggregate demand and prevent the liquidity trap [cf. Eq. A.6]]. Nonetheless, the following result establishes that the economy experiences an anticipated liquidity trap in state $L$, as long as the probability of the state is sufficiently low, and the demand for housing in the counterfactual state $H$ is sufficiently high.

Lemma 3. Consider the modified model with the ex-ante date -1 , with the initial conditions, $h_{-1}=h^{*}\left(1+\lambda^{H}\right)$ and $k_{-1}=k^{*}$. Suppose $\lambda^{H}>\bar{b}_{0}^{\text {sep }}\left(k^{*}\right)$, where $\bar{b}_{0}^{\text {sep }}\left(k^{*}\right)$ denotes the overbuilding threshold in (A.6) given $k_{0}=k^{*}$. There exists $\bar{\pi}<1$ such that, if $\pi^{H} \in(\bar{\pi}, 1)$, then the equilibrium features a liquidity trap in state $L$ of date 0 (but not in any other dates or states).

The equilibrium path starting the high-demand state $H$ of date 0 is straightforward. It solves the neoclassical planning problem (9) with a steady level of residential investment given by, $i_{t}^{h}=\delta\left(1+\lambda^{H}\right) h^{*}$ for each $t \geq 0$. The zero lower bound does not bind and the rental rate of capital is given by $R_{0}^{H}=s^{\prime}\left(k_{0}\right)$. The equilibrium path starting the low-demand state $L$ of date 0 is characterized as in Lemma 2 given the (endogenous) level of overbuilding, $b_{0}=\lambda^{H}$.

Next consider a constrained planner who can (only) control households' date -1 allocations. As described in the main text, the planner optimally chooses $h_{0, p l}=h_{0}=\left(1+\lambda^{H}\right) h^{*}$. However, the planner's choice of nonresidential capital, $k_{0, p l}$, is potentially different. To characterize this choice, let $V_{0}^{H}\left(k_{0}, h_{0}\right)$ and $V_{0}^{L}\left(k_{0}, h_{0}\right)$ denote the welfare of the representative household in respectively states $H$ and $L$ of date 0 . The ex-ante constrained planning problem can then be written as,

$$
\begin{array}{ll} 
& \max _{c_{-1}, k_{0}} u\left(c_{-1}\right)+\beta\left(\pi^{H} V_{0}^{H}\left(k_{0}, h_{0}\right)+\left(1-\pi^{H}\right) V_{0}^{L}\left(k_{0}, h_{0}\right)\right), \\
\text { s.t. } & c_{-1}+k_{0}+h_{0, p l}=s\left(k_{-1}\right)+\left(1-\delta^{k}\right) k_{-1}+\left(1-\delta^{h}\right) h_{-1} .
\end{array}
$$


In particular, the planner optimally trades off the ex-ante consumption, $c_{-1}$, with investment, $k_{0}$, evaluating the benefits of the latter in the competitive equilibrium that will obtain in each state. The optimality condition for the problem is then given by

$$
u^{\prime}\left(c_{-1}\right)=\beta\left(\pi^{H} \frac{d V_{0}^{H}\left(k_{0}, h_{0}\right)}{d k_{0}}+\left(1-\pi^{H}\right) \frac{d V_{0}^{L}\left(k_{0}, h_{0}\right)}{d k_{0}}\right) .
$$

We next derive $\frac{d V_{0}^{H}\left(k_{0}, h_{0}\right)}{d k_{0}}$ and $\frac{d V_{0}^{L}\left(k_{0}, h_{0}\right)}{d k_{0}}$, and establish Eq. 29). If state $H$ is realized, then the equilibrium solves the analogue of problem (9) (with appropriate modifications to capture the higher target level, $\left.\left(1+\lambda^{H}\right) h^{*}\right)$. Then, the envelope theorem implies,

$$
\frac{d V_{0}^{H}\left(k_{0}, h_{0}\right)}{d k_{0}}=\left(s^{\prime}\left(k_{0}\right)+1-\delta^{k}\right) u^{\prime}\left(c_{0}^{H}\right) .
$$

Suppose instead state $L$ is realized. We conjecture (and verify in Proposition 4) that the planner's allocation also features a liquidity trap in this state. The continuation allocation is characterized by Lemma 2, and it solves problem (A.7) with $h_{1}=h^{*}$ (since we rule out ex-post policies). This problem implies that the following variables are constant, $k_{1}=\bar{k}, c_{0}=\bar{c}_{0}, h_{1}=h^{*}$ (and thus, the continuation value $V_{1}$ is also constant). In contrast, output and employment, $y_{0}\left(k_{0}\right), l_{0}\left(k_{0}\right)$, are determined as implicit functions of $k_{0}$. Implicitly differentiating the aggregate demand constraint A.8 with respect to $k_{0}$, we obtain,

$$
\frac{d l_{0}}{d k_{0}}=-\frac{F_{k}\left(k_{0}, l_{0}\right)+\left(1-\delta^{k}\right)}{F_{l}\left(k_{0}, l_{0}\right)}=-\left(F_{k}\left(k_{0}, l_{0}\right)+\left(1-\delta^{k}\right)\right) \frac{\left(1-\tau_{0}\right) u^{\prime}\left(\bar{c}_{0}\right)}{v^{\prime}\left(l_{0}\right)} .
$$

Here, the second equality substitutes the labor wedge from Eq. A.5. Differentiating the objective function with respect to $k_{0}$, and using this expression, we further obtain,

$$
\frac{d V_{0}^{L}\left(k_{0}, h_{0}\right)}{d k_{0}}=-v_{0}^{\prime}\left(l_{0}\right) \frac{d l_{0}}{d h_{1}}=\left(1-\tau_{0}\right)\left(F_{k}\left(k_{0}, l_{0}\right)+\left(1-\delta^{k}\right)\right) u^{\prime}\left(\bar{c}_{0}\right) .
$$

Plugging in $R_{0}^{L}=\left(1-\tau_{0}\right) F_{k}\left(k_{0}, l_{0}\right)$ from Lemma 2 implies,

$$
\frac{d V_{0}^{L}\left(k_{0}, h_{0}\right)}{d k_{0}}=\left(R_{0}^{k}+\left(1-\tau_{0}\right)\left(1-\delta^{k}\right)\right) u^{\prime}\left(\bar{c}_{0}\right)
$$

Plugging the expressions for $\frac{d V_{0}^{H}\left(k_{0}, h_{0}\right)}{d k_{0}}$ and $\frac{d V_{0}^{L}\left(k_{0}, h_{0}\right)}{d k_{0}}$ into $A .10$ implies the planner's optimality condition (29). Appendix B proves Propositions 5 and 6 , and completes the welfare analysis in Section 5.2 . 


\section{B Online Appendix: Omitted proofs}

\section{B.1 Proofs for the baseline model}

This section presents the proofs of the results for the baseline model and its variants analyzed in Sections 2, 3 and 4 .

Characterization of the Efficient Benchmark. Consider a planner that maximizes households' welfare starting date $t$ onwards, given the initial state $h_{t}, k_{t}$, and the feasibility constraints of the economy. In view of the preferences (2), the planner chooses the same level of $i_{t}^{h}$ as the representative household given by Eq. (3). The planner's problem can then be written as,

$$
\begin{aligned}
& \max _{\left\{\hat{c}_{\tilde{t}}, l_{\tilde{t}}, k_{\tilde{t}+1},\left[l_{\tilde{t}}(\nu), k_{\tilde{t}}(\nu)\right]_{\nu}\right\}_{\tilde{t}=t}^{\infty}} \sum_{\tilde{t}=t}^{\infty} \beta^{\tilde{t}} u\left(\hat{c}_{\tilde{t}}-\nu\left(l_{\tilde{t}}\right)\right), \\
& \text { s.t. } \hat{c}_{\tilde{t}}+k_{\tilde{t}+1}+i_{\tilde{t}}^{h} \leq \hat{y}_{\tilde{t}}, \text { where } \\
\hat{y}_{\tilde{t}}= & \left(\int_{0}^{1}\left(F\left(k_{\tilde{t}}(\nu), l_{\tilde{t}}(\nu)\right)\right)^{\frac{\varepsilon-1}{\varepsilon}} d \nu\right)^{\varepsilon /(\varepsilon-1)}, k_{\tilde{t}}=\int k_{\tilde{t}}(\nu) d \nu, \text { and } l_{\tilde{t}}=\int l_{\tilde{t}}(\nu) d \nu .
\end{aligned}
$$

By concavity, the planner chooses $k_{\tilde{t}}(\nu)=k_{\tilde{t}}$ and $l_{\tilde{t}}(\nu)=l_{\tilde{t}}$ for each $\tilde{t}$. The optimality condition for labor then implies Eq. (10). In view of these observations, the planner's problem reduces to the neoclassical problem (9). The solution $\left\{c_{\tilde{t}}, k_{\tilde{t}+1}\right\}_{\tilde{t}=t}^{\infty}$ is characterized as the solution to the neoclassical system of equations,

$$
\begin{aligned}
c_{\tilde{t}}+k_{\tilde{t}+1}+i_{\tilde{t}}^{h} & =s\left(k_{\tilde{t}}\right)+\left(1-\delta^{k}\right) k_{\tilde{t}}, \\
u^{\prime}\left(c_{\tilde{t}}\right) & =\beta\left(1+s^{\prime}\left(k_{\tilde{t}}\right)-\delta^{k}\right) u^{\prime}\left(c_{\tilde{t}+1}\right),
\end{aligned}
$$

along with a transversality condition. The steady-state to this system is characterized by,

$$
\beta\left(1-\delta^{k}+s^{\prime}\left(k^{*}\right)\right)=1 \text { and } c^{*}=s\left(k^{*}\right)-\delta k^{*}-\delta h^{*} .
$$

Starting with any $k_{t}, h_{t}$, there is an interior solution to the system in (B.1) that converges to the steady state (as long as the residential investment is feasible at all dates, which we assume). Since the planner's problem is strictly concave, this is also the unique solution, completing the characterization of the efficient benchmark.

Proof of Lemma 1. First consider the case $r_{t+1}>0$. In this case, the monetary policy implements the efficient allocation with $l_{t}=l_{t}^{*}$ and $y_{t}=s\left(k_{t}\right)$. In addition, the 
first order conditions for problems (10) and (4) further imply, $F_{l}\left(k_{t}, l_{t}^{*}\right)=v^{\prime}\left(l_{t}^{*}\right)=w_{t}$. Combining this with Eq. (13) implies that the labor wedge is zero, $\tau_{t}=0$. Combining Eqs. (13) and (10) then imply the rental rate of capital is given by $F_{k}\left(k_{t}, l_{t}^{*}\right)=s^{\prime}\left(k_{t}\right)$, completing the proof for the first part.

Next consider the case $r_{t+1}=0$. In this case, Eq. (13) implies $F_{l}\left(k_{t}, l_{t}\right) \geq v^{\prime}\left(l_{t}\right)$. This in turn implies that $l_{t} \in\left[0, l_{t}^{*}\right]$. By feasibility, net output satisfies

$$
y_{t}=c_{t}+i_{t}^{h}+i_{t}^{h}=F\left(k_{t}, l_{t}\right)-v\left(l_{t}\right)
$$

This right hand side is strictly increasing in $l_{t}$ over the range $\left[0, l_{t}^{*}\right]$. The minimum and the maximum are respectively given by 0 and $s\left(k_{t}\right)$, which implies $y_{t} \in\left[0, s\left(k_{t}\right)\right]$. Moreover, given $y_{t}$ that satisfies these resource constraints, there is a unique solution to problem (12), which we denote by $L\left(k_{t}, y_{t}\right)$. Combining this with Eq. (13), we further obtain the labor wedge as,

$$
1-\tau_{t}=\frac{v^{\prime}\left(l_{t}\right)}{F_{l}\left(k_{t}, l_{t}\right)}=\frac{v^{\prime}\left(L\left(k_{t}, y_{t}\right)\right)}{F_{l}\left(k_{t}, L\left(k_{t}, y_{t}\right)\right)} .
$$

Plugging this into Eq. (13) for capital, we obtain the rental rate of capital as,

$$
R_{t}=\frac{v^{\prime}\left(L\left(k_{t}, y_{t}\right)\right)}{F_{l}\left(k_{t}, L\left(k_{t}, y_{t}\right)\right)} F_{k}\left(k_{t}, L\left(k_{t}, y_{t}\right)\right) \equiv R\left(k_{t}, y_{t}\right)
$$

where the last equality defines the function $R(\cdot)$. Note that $R\left(k_{t}, y_{t}\right) \leq s^{\prime}\left(k_{t}\right)$ since the labor wedge is nonnegative. It can also be checked that $R_{k}<0$ and $R_{y}>0$, completing the proof.

Proof of Proposition 1. We first claim that the equilibrium at date 1 starting with $h_{1}=h^{*}$ and $k_{1} \leq \bar{k}$ is the same as the efficient benchmark. Recall that the efficient benchmark is characterized as the solution to the neoclassical system in $(B .1)$. Since $i_{t}^{h}=\delta h^{*}$ for each $t$, the neoclassical system is stationary. It can then be seen that the capital stock in the efficient benchmark converges monotonically to $k^{*}<\bar{k}$ starting with $k_{1} \leq \bar{k}$. In particular, the capital stock remains weakly below $\bar{k}$ at all dates. This implies $r_{t+1}=s^{\prime}\left(k_{t+1}\right)-\delta^{k} \geq s^{\prime}(\bar{k})-\delta^{k} \geq 0$ for each $t \geq 1$. That is, the zero lower bound constraint does not bind at any date $t \geq 1$. This in turn implies that the monetary policy in (11) exactly replicates the efficient benchmark starting date 1 , proving our claim. Note also that consumption at date 1 is given by $c_{1}=C\left(k_{1}\right)$, where $C(\cdot)$ is an increasing function that describes the solution to the neoclassical system $B .1$. 
To characterize the equilibrium at date 0 , we define $K_{1}\left(r_{0}\right)$ for each $r_{0} \geq 0$ as the solution to

$$
s^{\prime}\left(K_{1}\left(r_{0}\right)\right)-\delta^{k}=r_{0} .
$$

Note that $K_{1}\left(r_{0}\right)$ is decreasing in the interest rate, with $K_{1}(0)=\bar{k}$ and $\lim _{r_{0} \rightarrow \infty} K_{1}\left(r_{0}\right)=0$. Similarly, define the function $C_{0}\left(r_{0}\right)$ as the solution to the Euler equation

$$
u^{\prime}\left(C_{0}\left(r_{0}\right)\right)=\beta\left(1+r_{0}\right) u^{\prime}\left(C\left(K_{1}\left(r_{0}\right)\right)\right) .
$$

Note that $C_{0}\left(r_{0}\right)$ is decreasing in the interest rate, with $C_{0}(0)=\bar{c}_{0}$ and $\lim _{r_{0} \rightarrow \infty} C_{0}\left(r_{0}\right)=0$. Finally, define the aggregate demand function

$$
Y_{0}\left(r_{0}\right)=C_{0}\left(r_{0}\right)+K_{1}\left(r_{0}\right)-\left(1-\delta^{k}\right) k_{0}+i_{0}^{h}
$$

Note that $Y_{0}\left(r_{0}\right)$ is also decreasing in the interest rate, with

$$
Y_{0}(0)=\bar{y}_{0} \text { and } \lim _{r_{0} \rightarrow \infty} Y_{0}\left(r_{0}\right)=i_{0}^{h}-\left(1-\delta^{k}\right) k_{0}
$$

Next consider the date 0 equilibrium for the case $b_{0} \leq \bar{b}_{0}$. Note that this implies $s\left(k_{0}\right) \leq \bar{y}_{0}=Y_{0}(0)$, and that we also have $\lim _{r_{0} \rightarrow \infty} Y_{0}\left(r_{0}\right)<s\left(k_{0}\right)$ (since we assume residential investment is feasible). By the intermediate value theorem, there is a unique equilibrium interest rate $r_{0} \in[0, \infty)$ such that $Y_{0}\left(r_{0}\right)=s\left(k_{0}\right)$. The equilibrium features $c_{0}=C_{0}\left(r_{0}\right)$ and $K_{1}\left(r_{0}\right)=k_{1}$, along with $y_{0}=s\left(k_{0}\right)$ and $l_{0}=l_{0}^{*}$.

Next consider the date 0 equilibrium for the case $b_{0}>\bar{b}_{0}$. In this case, $Y_{0}(0)<s\left(k_{0}\right)$. Thus, the unique equilibrium features $r_{0}=0$ and $y_{0}=\bar{y}_{0}<s\left(k_{0}\right)$. Consumption and investment are given by $c_{0}=\bar{c}_{0}$ and $k_{1}=\bar{k}_{1}$. Labor supply $l_{0}$ is determined as the unique solution to $(12)$ over the range $l_{0} \in\left(0, l_{0}^{*}\right)$. Finally, Eq. A.4 implies the equilibrium output, $y_{0}=\bar{y}_{0}$, is declining in the initial overbuilding $b_{0}$.

In either case, it can also be checked that the economy reaches date 1 with $h_{1}=$ $h^{*}$ and $k_{1} \geq \min \left(k_{0}, k^{*}\right)$. Thus, the continuation equilibrium is characterized as described above, completing the proof.

Proof of Proposition 2. Note that the recession is triggered if $\bar{y}_{0}<s\left(k_{0}\right)$, where $\bar{y}_{0}$ is given by Eq. (21). Since $1-\delta^{h^{d}}>1-\delta^{h^{n}}$, increasing $b_{0}^{d}$ (while keeping $b_{0}=\left(b_{0}^{d}+b_{0}^{n}\right) / 2$ constant) reduces $\bar{y}_{0}$, proving the result.

Proposition 3 also requires the following assumption. 
Assumption 3. (i) $i^{h} \in\left[-\bar{c}_{T}, s(\bar{k})-\delta \bar{k}-\bar{c}_{0}\right)$ and (ii) $R\left(k_{0}, \tilde{y}_{0}\right)<\delta^{k}$, where $\tilde{y}_{0}=\bar{c}_{0}-\bar{c}_{T}+\bar{k}-\left(1-\delta^{k}\right) k_{0}$

Part (i) ensures that $i^{h}$ is not too low to induce zero aggregate demand, but also not too high so that a liquidity trap is possible. Part (ii) ensures that the worst possible shock $i^{h}=-\bar{c}_{T}$ is sufficient to induce a liquidity trap at date 0 .

Proof of Proposition 3. We first claim that the solution to Eq. (23) can be written as $k_{t}=K\left(y_{t}\right)$, where $K(\cdot)$ is an increasing function over $(0, s(\bar{k}))$. To this end, consider some $y \in(0, s(\bar{k}))$. Let $\tilde{k}<\bar{k}$ denote the unique capital level such that $y=s(\tilde{k})$. Note that

$$
R(\tilde{k}, y)=s^{\prime}(\tilde{k})>\delta^{k} \text { and } R(\bar{k}, y)<s^{\prime}(\bar{k})=\delta^{k} .
$$

Here, the former inequality follows since $\tilde{k}<\bar{k}$, and the latter inequality follows from Lemma 1 since $y<s(\bar{k})$. Since $R_{k}<0$, there exists a unique $K(y) \in(\tilde{k}, \bar{k})$ such that $R(K(Y), Y)-\delta^{k}=0$. Thus, the function $K(\cdot)$ is well defined. Note also that $K(\cdot)$ is continuous and strictly increasing. Note also that $\lim _{y \rightarrow 0} K(y)=0$ and $K(s(\bar{k}))=\bar{k}$.

Given the function $K(\cdot)$, the path of capital can be written as the solution to the system,

$$
\begin{aligned}
k_{t} & =K\left(y_{t}\right) \\
\text { and } y_{t} & =Y_{t}\left(k_{t}\right) \equiv \bar{c}_{t}+k_{t+1}+i^{h}-\left(1-\delta^{k}\right) k_{t} .
\end{aligned}
$$

Here, the second equation defines the function $Y_{t}\left(k_{t}\right)$, which is strictly decreasing in $k_{t}$. Hence, the current level of output and capital are satisfied as the intersection of a strictly increasing and a strictly decreasing relation. We next claim that, given $\bar{c}_{t}$ and $k_{t+1} \in(0, \bar{k}]$, there is a unique solution to the system in $\left.B .2\right)$. To see this, first note that the boundary conditions at $y_{t}=0$ and $k_{t}=0$ respectively satisfy,

$$
\lim _{y \rightarrow 0} K(y)=0, Y_{t}(0) \geq 0
$$

where the inequality follows since Assumption 3(i) implies $\bar{c}_{t}+i^{h} \geq 0$ for each $t$. Next note the following boundary conditions at $y_{t}=s(\bar{k})$ and $k_{t}=\bar{k}$,

$$
K(s(\bar{k}))=\bar{k} \text { and } Y_{t}(\bar{k}) \leq \bar{c}_{t}+\delta \bar{k}+i^{h}<s(\bar{k}),
$$


where the strict inequality follows by using Assumption 3(i) together with $\bar{c}_{t}<\bar{c}_{0}$. It follows that there is a unique solution to the system $B .2$ which also satisfies $k_{t} \in(0, \bar{k})$ and $y_{t} \in(0, s(\bar{k}))$. It can also be seen that $k_{t}$ and $y_{t}$ are both strictly increasing in $i^{h}$.

Since the solution satisfies $k_{t}<\bar{k}$, we can reiterate the same analysis to solve for $k_{t-1} \in(0, \bar{k})$ and $y_{t-1} \in(0, s(\bar{k}))$. By induction, we obtain a unique equilibrium path $\left\{k_{1}, y_{1}\right\}_{t=0}^{T-1}$. Note also that $k_{0}$ is given, and output at date 0 is determined by

$$
y_{0}=Y_{0}\left(k_{0}\right)=\bar{c}_{0}+k_{1}+i^{h}-\left(1-\delta^{k}\right) k_{0}
$$

Note that the path $\left\{k_{1}, y_{1}\right\}_{t=0}^{T-1}$ as well as the initial output $y_{0}$ are strictly increasing in $i^{h}$.

We next claim there is a liquidity trap at date $0, y_{0}<s\left(k_{0}\right)$, as long as the residential investment is below a threshold. Note that $y_{0}<s\left(k_{0}\right)$ if and only if $R\left(k_{0}, y_{0}\right)<\delta^{k}$. First consider the claim for the worst possible shock, $i^{h}=-\bar{c}_{T}$. In this case, the output at date 0 satisfies,

$$
y_{0} \leq \bar{c}_{0}-\bar{c}_{T}+\bar{k}-\left(1-\delta^{k}\right) k_{0}
$$

Combining this with Assumption 3(ii), we obtain $R\left(k_{0}, y_{0}\right)<\delta^{k}$, proving the claim. Since $y_{0}$ is strictly increasing in $i^{h}$, there exists $i_{1}^{h}>-\bar{c}_{T}$ such that $y_{0}=s\left(k_{0}\right)$. It follows that $y_{0}<s\left(k_{0}\right)$ whenever $i^{h}<i^{h, 1}$, proving the first part of the proposition.

Similarly, we claim that the worst allowed shock $i^{h}=-\bar{c}_{T}$ induces $k_{1}<k_{0}$. To see this, consider the output at date 1 given by,

$$
y_{1}=\bar{c}_{1}-\bar{c}_{T}+k_{2}-\left(1-\delta^{k}\right) k_{1} \leq \bar{c}_{0}-\bar{c}_{T}+\bar{k}-\left(1-\delta^{k}\right) k_{1}
$$

Combining this with Assumption 3(ii), we obtain $R\left(k_{0}, y_{1}\right)<\delta^{k}$. This in turn implies $k_{1}=K\left(y_{1}\right)<k_{0}$, proving the claim. Since $k_{1}$ is strictly increasing in $i^{h}$, there exists $i^{h, 2} \leq i^{h, 1}$ and $i^{h, 2}>-\bar{c}_{T}$ such that $k_{1}=k_{0}$. It follows that $k_{1}<k_{0}$ whenever $i^{h}<i^{h, 2}$, completing the proof.

\section{B.2 Proofs for the extension with income-trackers}

Lemma 4. The income-trackers' wage level is given by Eq. A.2 for some function $\psi\left(k_{t}, y_{t}\right)$, which has the following properties:

(i) $\psi\left(k_{t}, y_{t}\right)=1-\tau_{t}=\frac{v^{\prime}\left(l_{t}\right)}{F_{l}\left(k_{t}, l_{t}\right)}$,

(ii) $\psi\left(k_{t}, y_{t}\right)=1$ if $r_{t+1}>0$, and $\psi\left(k_{t}, y_{t}\right) \in[0,1]$ if $r_{t+1}=0$, 
(iii) $\psi\left(k_{t}, y_{t}\right)$ is strictly decreasing in $k_{t}$, and strictly increasing in $y_{t}$.

Proof. As in the proof of Lemma 1, let $L(k, y)$ denote the labor supply corresponding to capital level $k \in(0, \bar{k}]$ and output $y \in(0, s(k)]$. Next consider the analogue of Problem (8) that also includes firms' demand for hand-to-mouth labor. The firm's optimization in this case implies

$$
w^{t r}\left(k_{t}, y_{t}\right)=\left(1-\tau_{t}\right) \eta^{t r},
$$

where $\tau_{t} \geq 0$ is the Lagrange multiplier on the demand constraint. As before, the same problem also implies that $\tau_{t}$ is equal to the labor wedge, that is:

$$
1-\tau_{t}=\frac{v^{\prime}\left(L\left(k_{t}, y_{t}\right)\right)}{F_{l}\left(k_{t}, L\left(k_{t}, y_{t}\right)\right)} \equiv \psi\left(k_{t}, y_{t}\right) .
$$

Here, the last line defines the function $\psi\left(k_{t}, y_{t}\right)$. Combining these expressions proves the first part. Recall that the labor wedge satisfies $\tau_{t}=0$ if $r_{t+1}=0$, and $\tau_{t} \in[0,1]$ if $r_{t+1}>0$, proving the second part. It can also be checked that $\psi_{k}<0$ and $\psi_{y}>0$, completing the proof.

Proposition 7 requires a strengthening of Assumption 3(i). Assumption 3(ii) remains unchanged.

Assumption $3^{\text {tr }}$.(i) $i^{h} \in\left[-\left(\bar{c}_{T}-\eta^{\text {tr }} l^{t r}\right), s(\bar{k})-\delta \bar{k}-\bar{c}_{0}\right)$.

Proof of Proposition 7. Let $K(y)$ denote the function defined in the proof of Proposition 3 that describes the break-even capital level $k_{t}=K\left(y_{t}\right)$ given output $y_{t}$. Eqs. 23) and A.3 can then be written as, $y_{t}=f\left(y_{t}\right)$ for each $t \geq 1$, where

$$
f\left(y_{t}\right) \equiv \bar{c}_{t}+k_{t+1}-\left(1-\delta^{k}\right) K\left(y_{t}\right)+i^{h}+\left(\psi\left(K\left(y_{t}\right), y_{t}\right)-1\right) \eta^{t r} l^{t r} .
$$

The output at date 0 is separately characterized as the solution to Eq. A.3 with the initial $k_{0}$ (as opposed to $K\left(y_{0}\right)$ ).

We next claim that, given $k_{t+1} \in(0, \bar{k}]$, there exists a solution to $(B .3)$ over the range $y_{t} \in(0, s(\bar{k}))$. To see this, note that

$$
\lim _{y_{t} \rightarrow 0} f\left(y_{t}\right)>\bar{c}_{T}+i^{h}-\eta^{t r} l^{t r} \geq 0,
$$

where the first inequality uses $\bar{c}_{t} \geq \bar{c}_{T}, k_{t+1}>0$ and $\psi \geq 0$, and the second inequality 
uses Assumption $3^{\text {tr }}(\mathrm{i})$. Next note that

$$
f(s(\bar{k})) \leq \bar{c}_{0}+\bar{k}-\left(1-\delta^{k}\right) k_{0}+i^{h}<s(\bar{k})
$$

where the first inequality uses $\bar{c}_{t} \leq \bar{c}_{0}, k_{t+1} \leq \bar{k}$ and $\psi \leq 1$, and the second inequality uses Assumption $3^{\text {tr }}$ (ii). Combining the last two inequalities implies the existence of a solution $y_{t} \in(0, s(\bar{k}))$ along with $k_{t}=K\left(y_{t}\right) \in(0, \bar{k})$. Applying the same argument recursively, we obtain the path $\left\{k_{t}, y_{t}\right\}_{t=1}^{T-1}$. By the same argument, there exists $y_{0} \in(0, s(\bar{k}))$ that solves Eq. A.3 with the initial $k_{0}$.

Note that there could be multiple solutions to Eq. (B.3) [and Eq. (A.3) for date 0 ], which could generate multiple equilibria. We establish the desired results for the "best" equilibrium that has the highest capital and net output, which also implies the results for any other equilibrium. To this end, let $y_{t}^{b}$ denote the supremum over all $y_{t}$ 's that solve Eq. B.3 [and Eq. A.3 for date 0] given $k_{t+1}^{b}$. Then let $k_{t}^{b}=K\left(y_{t}^{b}\right)$. By induction, we obtain a particular solution to Eq. (B.3 [and Eq. B.3 for date 0]. It is easy to show that this is the "best" solution in the sense that any other solution satisfies $k_{t} \leq k_{t}^{b}$ and $y_{t} \leq y_{t}^{b}$ for each $t$.

We next claim that there is a liquidity trap at date $0, y_{0}^{b}<s\left(k_{0}\right)$, or equivalently $R\left(k_{0}, y_{0}^{b}\right)<\delta^{k}$, as long as $i^{h}$ is below a threshold. First consider the claim for the worst possible shock $i^{h}=-\left(\bar{c}_{T}-\eta^{t r} l^{t r}\right)$. In this case, output at time 0 satisfies,

$$
\begin{aligned}
y_{0}^{b} & =\bar{c}_{0}-\bar{c}_{T}+k_{1}^{b}-\left(1-\delta^{k}\right) k_{0}+(\psi-1) \eta^{t r} l^{t r} \\
& \leq \bar{c}_{0}-\bar{c}_{T}+\bar{k}-\left(1-\delta^{k}\right) k_{0} .
\end{aligned}
$$

Combining this with Assumption 3(ii), we obtain $R\left(k_{0}, y_{0}^{b}\right)<\delta^{k}$, proving the claim for the worst possible shock. As in the proof of Proposition 3, this further implies that there exists $i^{h, 1}>-\left(\bar{c}_{T}-\eta^{t r} l^{t r}\right)$ such that there is a liquidity trap at date 0 if and only if $i^{h}<i^{h, 1}$. This completes the proof of the first part of the proposition.

To prove the second part, first note that $y_{t}^{b}<s\left(k_{t}^{b}\right)$ also implies $\psi_{t}\left(k_{t}^{b}, y_{t}^{b}\right)<1$ for each $t \in\{0, . ., T-1\}$. Eqs. $B .3$ and $A .3$ then imply that $y_{t}^{b}$ is strictly decreasing in $l^{t r}$ for each $t \in\{0, . ., T-1\}$. Next note that the required inequality can be rewritten as,

$$
\bar{c}_{0}-c^{*}<\left(1-\psi\left(k_{0}, y_{0}^{b}\right)\right) \eta^{t r} l^{t r} .
$$

Since $y_{0}^{b}$ is strictly decreasing in $l^{t r}$, so is the expression $\psi\left(k_{0}^{b}, y_{0}^{b}\right)$. Thus, there 
exists $l_{1}^{t r}$ such that $B .4$ holds for the best equilibrium path, $\left\{k_{t}^{b}, y_{t-1}^{b}\right\}_{t=0}^{T-1}$ if and only if $l^{t r}>l_{1}^{t r}$. Note also that any other equilibrium features $y_{0} \leq y_{0}^{b}$, and thus $\psi\left(k_{0}, y_{0}\right) \leq \psi\left(k_{0}, y_{0}^{b}\right)$. It follows that, as long as $l^{t r}>l_{1}^{t r}$, the inequality in $B .4$ holds for any equilibrium, completing the proof.

\section{B.3 Proofs for the policy analysis in Section 5 and Appendix A.2}

Proof of Lemma 2. Most of the proof is described in Appendix A.2. If $b_{0}<\bar{b}_{0}^{\text {sep }}$, then the maximum aggregate demand is above the efficient level, $\bar{y}_{0}>y_{0}^{*, s e p}$. In this case, the liquidity trap constraint does not bind and outcomes are efficient. If instead $b_{0}>\bar{b}_{0}^{s e p}$, then output is below the efficient level and it is determined by aggregate demand, $y_{0}=\bar{y}_{0}<y_{0}^{*, s e p}$. The employment is also below the efficient level, $l_{0}<l_{0}^{*, s e p}$, and it is characterized by solving, $y_{0}=\bar{y}_{0}=F\left(k_{0}, l_{0}\right)$. The labor wedge is characterized by solving, $1-\tau_{0}=\frac{v_{0}^{\prime}\left(l_{0}\right)}{F_{l}\left(k_{0}, l_{0}\right) u^{\prime}\left(\bar{c}_{0}\right)}$, and it satisfies $\tau_{0}>0$.

For future reference, note also that the employment level can also be written as a function, $L\left(k_{0}, y_{0}\right)$, as in the proof of Lemma 1. This also implies the labor wedge can be written as a similar function,

$$
\tau\left(k_{0}, y_{0}\right)=1-\frac{v_{0}^{\prime}\left(L\left(k_{0}, y_{0}\right)\right)}{F_{l}\left(k_{0}, L\left(k_{0}, y_{0}\right)\right) u^{\prime}\left(\bar{c}_{0}\right)} .
$$

It can be checked that function, $\tau(\cdot)$, is increasing in $k_{0}$ and decreasing in $y_{0}$.

Proof of Proposition 4. We first show that the planner's marginal utility, $\left.\frac{d_{+} W_{0, p l}\left(h_{1}\right)}{d h_{1}}\right|_{h_{1}=h^{*}}$, is increasing in the labor wedge, $\tau_{0}$. Note that the Euler equation in problem (A.7) implies,

$$
\left.\frac{d c_{0}}{d h_{1}}\right|_{h_{1}=h^{*}}=\frac{\beta u^{\prime \prime}\left(C\left(h^{*}\right)\right)}{u^{\prime \prime}\left(\bar{c}_{0}\right)} C^{\prime}\left(h^{*}\right)>0 .
$$

Here, the inequality follows because the solution to the neoclassical problem (9) implies $C^{\prime}\left(h^{*}\right)>0$. Note also that the derivative $\left.\frac{d c_{0}}{d h_{1}}\right|_{h_{1}=h^{*}}$ is independent of $b_{0}$ or $\tau_{0}$. Combining this with Eq. 27) proves that $\left.\frac{d_{+} W_{0, p l}\left(h_{1}\right)}{d h_{1}}\right|_{h_{1}=h^{*}}$ is increasing $\tau_{0}$.

Next note from the proof of 2 that the labor wedge, $\tau_{0}$, is strictly decreasing in aggregate demand, $y_{0}=\bar{y}_{0}$. Since the maximum demand, $\bar{y}_{0}$, in Eq. (A.4) is strictly decreasing in overbuilding, $b_{0}$, this implies that the labor wedge is strictly increasing in overbuilding, $b_{0}$. This in turn implies that the planner's marginal 
utility, $\left.\frac{d_{+} W_{0, p l}\left(h_{1}\right)}{d h_{1}}\right|_{h_{1}=h^{*}}$, is strictly increasing in $b_{0}$. It can also be checked that $\left.\frac{d_{+} W_{0, p l}\left(h_{1}\right)}{d h_{1}}\right|_{h_{1}=h^{*}}>0$ for sufficiently high levels of $b_{0}$. Let $\tilde{b}_{0}>\bar{b}_{0}^{\text {sep }}$ denote the level of overbuilding such that $\left.\frac{d_{+} W_{0, p l}\left(h_{1}\right)}{d h_{1}}\right|_{h_{1}=h^{*}}=0$. It follows that, $\left.\frac{d_{+} W_{0, p l}\left(h_{1}\right)}{d h_{1}}\right|_{h_{1}=h^{*}}>0$ if and only if $b_{0}>\tilde{b}_{0}$. This also implies $h_{1, p l}>h^{*}$ if and only if $b_{0}>\tilde{b}_{0}$.

Proof of Lemma 3. First consider the limiting case with $\pi^{H}=1$. In this case, given the initial conditions, the economy is at an efficient steady-state with,

$$
h_{t}=h^{*}\left(1+\lambda^{H}\right), k_{t}=k^{*} \text { and } c^{*}=s\left(k^{*}\right)-\delta^{h}\left(1+\lambda^{H}\right) h^{*}-\delta^{k} k^{*} .
$$

In particular, the competitive equilibrium features $k_{0}=k^{*}$. In this equilibrium, the economy does not feature a liquidity trap at date 0 or state $H$ of date 1 . In fact, we have $r_{1}=r_{2}^{H}=1 / \beta>0$. However, since $\lambda^{H}>\bar{b}_{0}^{\text {sep }}\left(k^{*}\right)$, the economy features a liquidity trap in the (zero probability) state $L$.

Next note that the capital choice in competitive equilibrium is a continuous function of the probability of the high state, $k_{0}\left(\pi^{H}\right)$. By Eq. (A.6), $\bar{b}_{0}^{\text {sep }}\left(k_{0}\right)$ is also a continuous function of $k_{0}$. It follows that there exists $\bar{\pi}^{1}$ (which could also be $\bar{\pi}^{1}=0$ ) such that $\lambda^{H}>\bar{b}_{0}^{\text {sep }}\left(k^{*}\right)$ if and only if $\pi^{H}>\bar{\pi}^{1}$. Similarly, note that the interest rates $r_{1}$ and $r_{2}^{H}$ are also continuous functions of $\pi^{H}$. Using continuity once again, there exists $\bar{\pi}^{2}<1$ (which could also be $\bar{\pi}^{2}=0$ ) such that the economy does not feature a liquidity trap at date 0 or at state $H$ if and only if $\pi^{H}>\bar{\pi}^{2}$. Taking $\bar{\pi}=\max \left(\bar{\pi}^{1}, \bar{\pi}^{2}\right)$ proves the statement.

Proof of Proposition 5. The planner's optimality condition (29) implies $k_{0, p l}<k_{0}$ since $\tau_{0}>0, \pi^{H}>0$, and $1-\delta^{k}>0$.

Proof of Proposition 6. In this case, the difference is that the planner can also control the ex-ante employment and net output, $l_{-1}, y_{-1}$, by deviating from the monetary policy in (11). Thus, the analogue of the planner's problem in $A .9$ ) is given by,

$$
\begin{array}{ll} 
& \max _{l_{-1}, y_{-1}, c_{-1}, k_{0}} u\left(c_{-1}\right)+\beta\left(\pi^{H} V_{0}^{H}\left(k_{0}, h_{0}\right)+\left(1-\pi^{H}\right) V_{0}^{L}\left(k_{0}, h_{0}\right)\right), \\
\text { s.t. } & c_{-1}+k_{0}+h_{0, p l}=s\left(k_{-1}\right)+\left(1-\delta^{k}\right) k_{-1}+\left(1-\delta^{h}\right) h_{-1}, \\
& \text { and } y_{-1}=f\left(k_{-1}, l_{-1}\right)-v\left(l_{-1}\right) \leq s\left(k_{-1}\right) .
\end{array}
$$

It is easy to check that the first order conditions maximize the net output, $y_{-1}=$ 
$s\left(k_{-1}\right)$ and $l_{-1}=l_{-1}^{*}$. This in turn leads to the same problem $A .9$ as before, as well as the same first order conditions (29). In particular, the planner sets the interest rate, $r_{0}=r_{0}^{*}$, which (by definition) replicates the statically efficient allocations at date -1 , completing the proof. 